\title{
POSITIVE AND NEGATIVE INFLUENCES PERCEIVED BY MINORITY STUDENTS TOWARD A CAREER IN ATHLETIC TRAINING.
}

A Dissertation
presented to
the Faculty of the Graduate School
at the University of Missouri-Columbia
In Partial Fulfillment
of the Requirements for the Degree
Doctor of Education
by
Stephen M. Nickell
Dr. David Stader, Dissertation Supervisor 2017


The undersigned, appointed by the dean of the Graduate School, have examined the dissertation entitled:

POSITIVE AND NEGATIVE INFLUENCES PERCEIVED BY MINORITY STUDENTS TOWARD A CAREER IN ATHLETIC TRAINING.

presented by Stephen M. Nickell,

a candidate for the degree Doctor of Education

and hereby certify that, in their opinion, it is worthy of acceptance.

Dr. David Stader, Major Advisor

Dr. Paul Watkins

Dr. Lisa Bertrand

Dr. Sharon Gunn 


\section{Acknowledgements}

I would like to acknowledge all the guidance and mentoring provided to me by my committee, especially Dr. David Stader and Dr. Paul Watkins. I would also like to thank my wife and children for their support during this process, because without them I would not be where I am today. 


\section{Table of Contents}

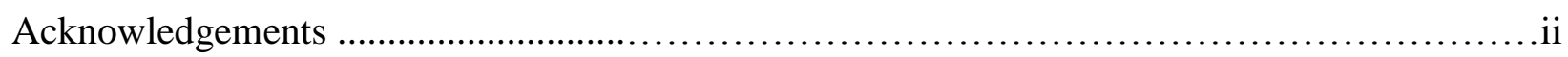

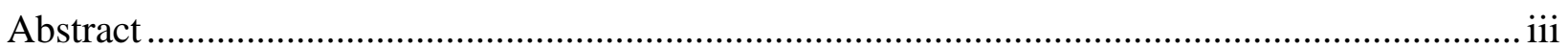

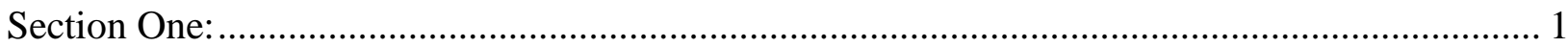

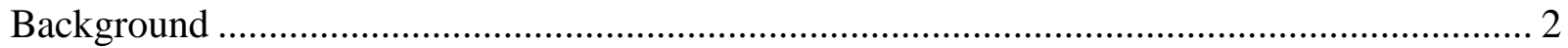

Statement of the Problem ................................................................................................ 3

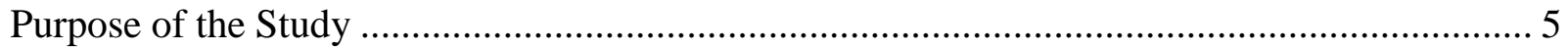

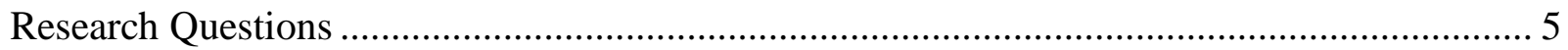

Conceptual/Theoretical Framework ………………….................................................. 6

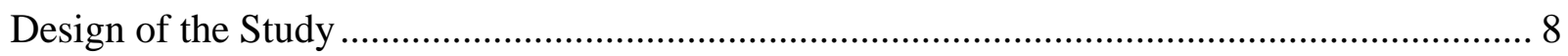

Definition of Key Terms .............................................................................................. 10

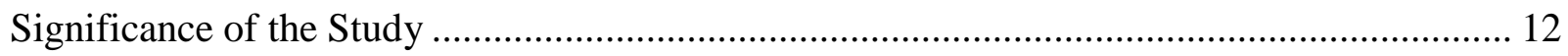

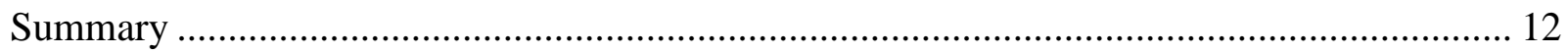

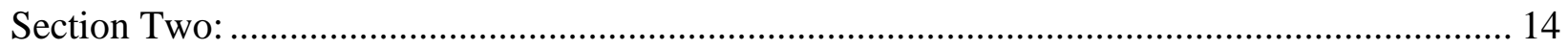

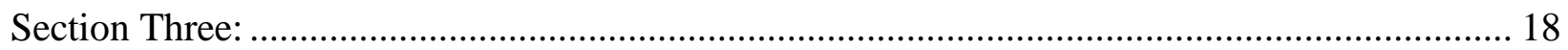

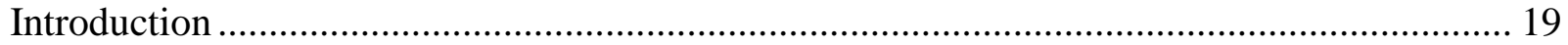

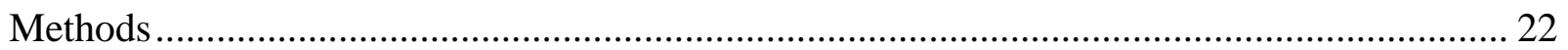

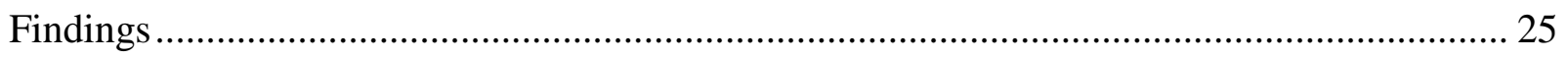

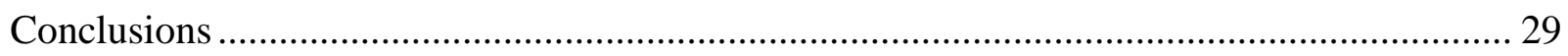

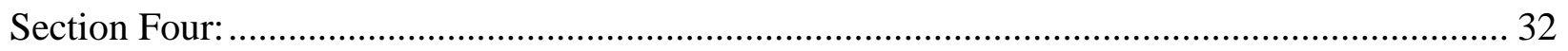

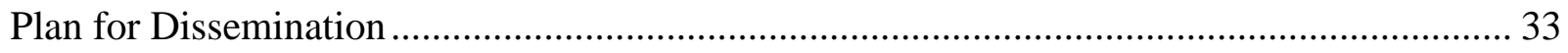

Type of Document and Rationale....................................................................................... 33

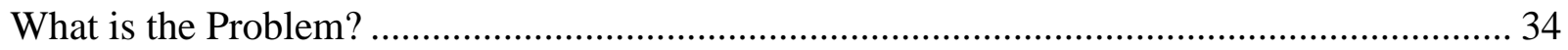

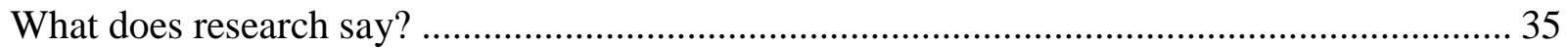

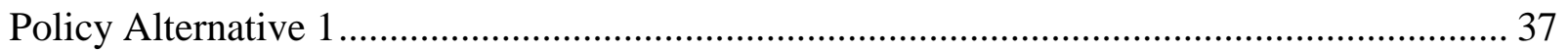

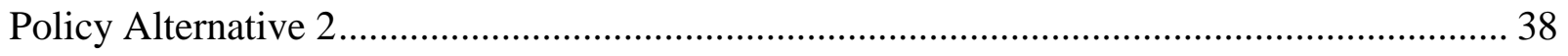




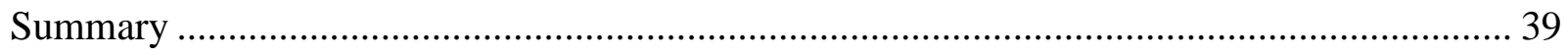

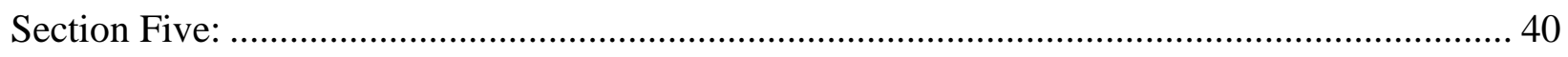

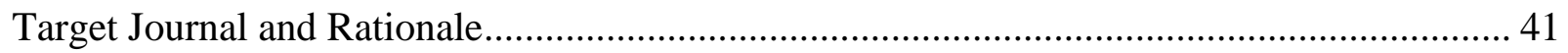

Outline of Proposed Content ..................................................................................... 41

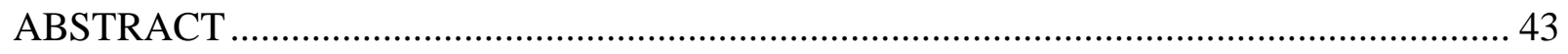

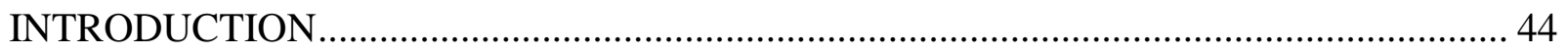

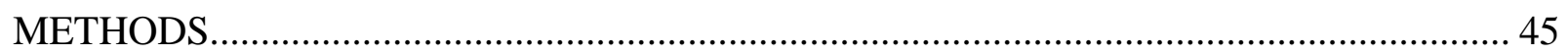

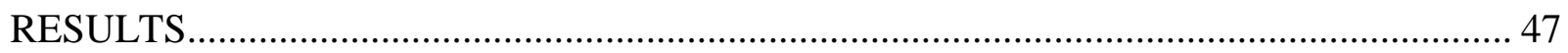

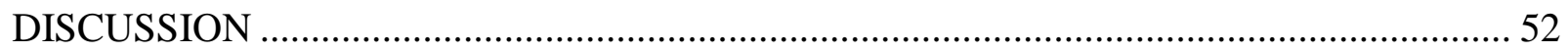

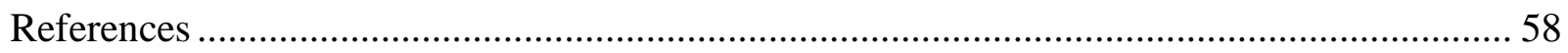

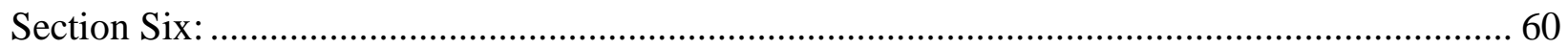

How has the dissertation influenced your practice as an educational leader? ....................... 61

How has the dissertation process influenced you as a scholar? ........................................ 62

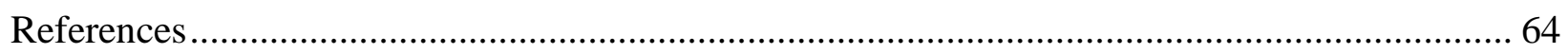

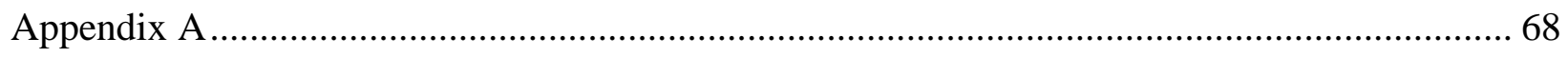

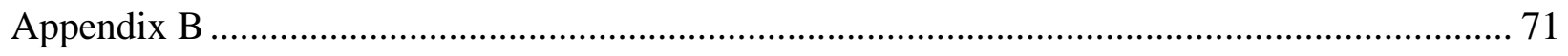

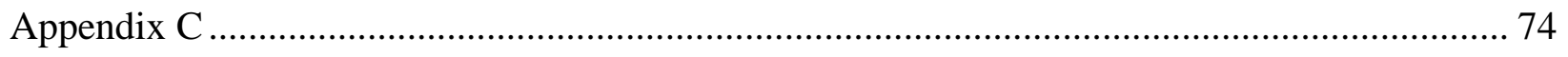

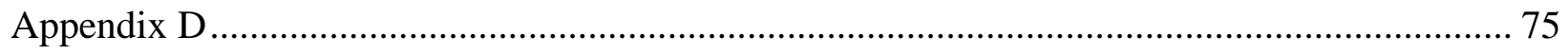

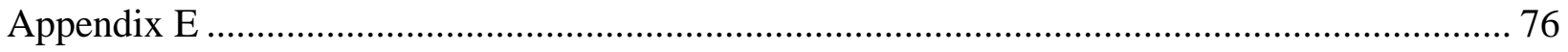

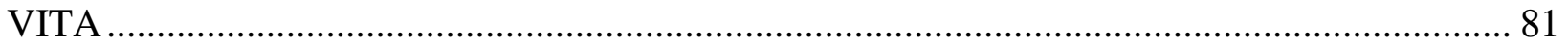


Positive and negative influences perceived by minority students

toward a career in athletic training.

Stephen M. Nickell

Dr. David Stader, Dissertation Supervisor

\begin{abstract}
Objective: The lack of diversity in the profession of athletic training is a concern as other healthcare professions increase. This research explores the influences and barriers that students perceive exist for choosing this profession and how race or ethnicity plays a role. Design and Setting: The study is a mixed methods research which is using a survey and interviews to provide data. The study is specifically looking at professional athletic training programs in the state of Missouri. Subjects: Undergraduate students currently enrolled in an accredited athletic training program in the State of Missouri. Measurements: Surveys were distributed and collected via Qualtrics and results were analyzed through a Kruskall-Wallis test and a MannWhitney U test. Interviews were transcribed and coded to determine common themes. Results: Significant differences were found between the responses of White and minority students on survey items related to college advisors, desire to help diverse patient populations, and a lack of role models in the profession. Conclusions: Policies related to the advising of potential athletic training students must be assessed to look at possible racial bias, and efforts to recruit diverse student populations should be a priority for athletic training education programs.
\end{abstract}

Key Words: Athletic Training Education, Professional Socialization, Critical Race Theory 


\section{Section One:}

Introduction to the Dissertation-in-Practice 


\section{Background}

One of the most disturbing trends in health care professions is the slow growth of diverse practitioners graduating from schools in the United States. Growth of diversity in these fields has increased over the last ten years, but at a significantly slower rate than what has been shown to occur in most professions (Sullivan \& Mittman, 2010). Specifically, in the field of athletic training, levels of diversity have had no change over the last ten years with the number of athletic trainers reporting themselves as White, non-Hispanic remaining at 82 percent (Ethnic Diversity Advisory Committee, 2010). Despite this trend, the profession of athletic training has done very little to help increase the number of diverse individuals entering the profession aside from encouraging diverse recruitment practices at the university level.

Athletic training education programs are designed to provide students with the knowledge, skills, and abilities to enter the profession upon graduation. Athletic training education programs are required to have two phases for students. The first phase is a preprofessional phase which involves the students taking prerequisite courses and observation of an athletic trainer. Upon completion of the pre-professional phase, students apply to enter the professional phase of the program. This application involves submission of a valid CPR certification, immunization records, physical exam, and an interview with the program faculty. The professional phase of an athletic training education program is composed of major specific coursework and clinical rotations under the direct supervision of an athletic trainer or other licensed health care professional. Clinical rotations occur during every semester a student is enrolled in the program, with most students completing between four to six semesters of clinical rotations often equaling over eight hundred hours of contact with patients (Commission for the Accreditation of Athletic Training Education, 2012). 
Part of the difficulty of recruiting a diverse student population in athletic training education programs is the major shifts which have been occurring within the education of these professionals. In 1997, there were two routes to becoming an athletic trainer. The first was to attend a university with an internship program for students to work within while taking courses. The second route was to be formally enrolled in an approved curricular program which leads towards certification. By 2004, all programs were required to become official degree programs, and an emphasis was placed on education over first-hand experience (Ebel, 1999). This has resulted in stagnant numbers of potential students of all races, who are unsure of entering into an academic program that is undergoing major changes for accreditation. Most programs have been focused on increasing their overall numbers just to make their major relevant and profitable, and have allowed a focus on recruiting diverse students to fall to the wayside. This research will look at the field of athletic training as it compares to other health care professions. Theories will be explored which may potentially explain the lack of diversity within the profession, and the effects that this has on education of athletic trainers.

\section{Statement of the Problem}

Within the field of athletic training, the level of minority professionals has remained stagnant over the last 10 years (Ethnic Diversity Advisory Committee, 2010). Though a great deal of research has been done in determining factors which affect minority enrollment in other health care fields, little to no research has been conducted in the field athletic training (Barfield et al., 2012; Henry, 2006; Hung et al., 2007; Melillo et al., 2013). A minority as defined in this research is any group of individuals who possesses specific characteristics which differ from the larger number of individuals within a specific group. Examples of racial minorities in the United States are Blacks, Native Americans, Asian Americans, and Hawaiians (Schaeffer, n.d.). There 
has also been little to no research on the perceptions of minority students in health care majors toward their socialization into the profession. This noticeable lack of research may explain why very few initiatives have been instituted by the National Athletic Trainers' Association (NATA) to help increase minority interest in the field.

Problem of Practice. A major challenge facing the profession of athletic training has been the consideration of changing the entry-level degree requirement for new athletic trainers from a bachelor's degree to a master's degree. In the recommendation paper presented to the NATA's Board of Directors (Executive Committee for Education, 2013), the issue of how this decision will affect the diversity issue in the profession was discussed. The recommendation stated, "When a profession increases its degree requirements, a common result is decreased minority representation in the student population and a resulting decline in practitioners" (Executive Committee for Education, 2013). It is for this very reason that it is imperative that the current lack of diversity within athletic training be examined. If the root causes already in place for low diversity enrollment in undergraduate programs are not determined and addressed, then the problem will only be exacerbated by an increase in the degree requirements.

Existing Gap in the Literature. Little to no research has considered other types of diversity within athletic training other than race and gender. The other types of diversity which could be considered are ethnicity, culture, religion, age, socioeconomic status, and sexual orientation. This research will focus on racial diversity for two reasons. As a result of little to no existing research or data availability for other types of diversity, there is no means for comparison between groups. The second reason is that there are a number of existing theories behind racial inequality, and therefore it gives a framework through which to view this issue. Specifically, this mixed 
methods research will be to determine what factors minority students perceive as being either a help or hindrance to their joining the field of athletic training.

\section{Purpose of the Study}

Looking at athletic training education programs is important for ascertaining what the root causes are for a lack of diversity in the profession. This is the entry point for any individual interested in becoming an athletic trainer, which means that the education programs are the essential point at which minority students decide to join the profession. What issues exist within these programs which potentially lead to a minority student not choosing this degree program? What factors play a role in the retention of minority students once they have enrolled in an athletic training program? As we look at finding the answers to these questions, we must consider how the White students enrolled in these programs view these same factors. We can then determine if race plays a role in enrollment or retention, or if this is a broader student issue. Through a mixed methods study, this research will not only look at the differences between both groups, but will also determine underlying reasons for decisions by individual minority participants.

\section{Research Questions}

The research questions guiding this study are:

1. What are minority students' perceptions of their socialization into the profession of athletic training?

2. What are White, non-Hispanic students' perceptions of their socialization into the profession of athletic training?

3. What factors influence minority students' decisions to choose athletic training as a major? 
4. What factors influence White, non-Hispanic students' decisions to choose athletic training as a major?

5. What factors do minority students' perceive as barriers when choosing athletic training as a major?

6. What factors do White, non-Hispanic students' perceive as barriers when choosing athletic training as a major?

\section{Conceptual/Theoretical Framework}

To accurately analyze the perceptions of minority students enrolled in athletic training education programs, and to attempt to remove my own biases as a White male in the profession of athletic training, this study will view these issues through the lens of critical race theory. Critical race theory has four distinct concepts which one must address and understand when considering racial issues. The first concept which must be considered is the idea that racism is "normal, not aberrant, in American society" (Delgado, 1995). The profession of athletic training must address and recognize the fact that there is an issue with inequity in its current educational model. Much like an addict, the profession must admit that there is a problem before a solution can be attempted.

The second concept within critical race theory, is the idea that critical race theory relies heavily on storytelling examples to help clearly define racial issues (Ladson-Billings, 1998).. To obtain these stories, the interviews of participants will become a crucial component of the dissertation.

Crenshaw (1988) gives us the third major concept of critical race theory. He presents the idea that racial issues cannot be addressed from within the current structure of most systems, because racial inequity is already inherent in the system. To make real change, one must 
radically overhaul the current structure of an organization (Crenshaw, 1988). If the NATA wants to correct the imbalance of minority representation in the profession, then it must completely rethink its approach to the recruitment of minority students.

The final concept of critical race theory is that most legislation instituted to benefit minorities has been more beneficial to Whites. Ladson-Billings (1998) gives the example that since the inception of affirmative action, White women have benefitted more than any other group. This goes back to the idea that athletic training must recognize that there is an issue, and then analyze their current diversity initiatives to determine who is truly benefiting from the policies.

When considering how new athletic trainers are brought into the profession, we look to the concept of professional socialization. Mooney (2007) defines professional socialization as, "the process through which novice practitioners are merged into the profession to become professional practitioners" (p. 75). Professional socialization has been little considered in the research for athletic training, but has been extensively studied with the field of nursing (Mooney, 2007; Hoffman et al., 2004; Secrest et al., 2003; Toit, 1995; Melia, 1997). Using nursing as a model, this research will attempt to make a connection between similar concepts of socialization within the literature and what is discovered during the data gathering. New nursing students have complained that policies are often set in stone and followed because that is what has always been done (Mooney, 2007). When we consider this through the lens of critical race theory we find that some of the policies which have kept minority students out of the profession may only be in place because that has been the traditional model. Mooney (2007) also reports that new nurses complained of feeling like they did not have a voice in their profession due to their lack of experience. Add the complication of being a minority student to this issue, and we can again see 
why many minorities may feel powerless within a profession predominated by Whites. Pitney et al. (2002) stated that the professional socialization of an athletic trainer to work in a NCAA

Division I setting requires that the athletic trainer have gone through a graduate assistantship at a Division I school. Since it has already been discussed, that minority's representation in postgraduate programs is lower than at the bachelor's level, it becomes apparent that this current model of professional socialization fails to take racial inequities into account. The idea that athletic training at the Division I level requires a great deal of time and dedication with very little reward financially or appreciation from the administration may also be a deterrent to a minority athletic trainer who may feel that they are already attempting overcome these issues (Pitney et al., 2002).

\section{Design of the Study}

Setting. The setting for this mixed methods study will be isolated to undergraduate accredited athletic training education programs in the state of Missouri. Certification in athletic training is accomplished through completion of an accredited athletic training education program and the successfully passing the Board of Certification exam. There are currently ten bachelor level programs throughout the state of Missouri. The setting chosen for this research was selected due to restrictions on travel for the researcher and availability of subjects.

Participants. The participants in this study will be all students currently enrolled in an undergraduate athletic training education program at the bachelor's level at the universities in the state of Missouri which offer this program. The students' participation in the research will be voluntary, and an informed consent will be obtained from each participant. A pilot study will be completed with students who are enrolled in the athletic training education program at Southeast Missouri State University. These students will not be included in the final research data to avoid 
any conflict of interest with the researcher who is the director of the Southeast Missouri State University athletic training education program.

Data Collection Tools. The initial portion of the data collection will be completed with a survey tool. The survey tool will be distributed to each participant along with the informed consent for the study. The survey tools this research will utilize are a combination of the Scale for Allied Health Enrollment Decision (SAHED) and the Scale for Allied Health Enrollment Barrier (SAHEB). Refer to Appendix A for a detailed description of the questions asked in the SAHED and Appendix B for the SAHEB. Both the SAHED and the SAHEB have undergone extensive analyses for their validity (Barfield et al., 2012). The participants will also be asked for demographic information about their race (Appendix C). This information will be vital for comparison of survey answers to look for any significant differences in the responses of minority students with their White peers.

Once the initial data collection gathering portion has been completed, further data gathering will be accomplished through semi-structured interviews (see Appendix D) with a purposeful sample of five to seven minority participants from universities surveyed in the state of Missouri. The participants interviewed will be selected based upon their availability and willingness to speak with the researcher. A cross section of institutions will be the goal for this portion of the data gathering process, but the availability of the participants and their location in relationship to the researcher will also be considered.

Data Analysis. The data from the survey responses will be compiled and analyzed through comparative statistics Responses to the survey questions will be analyzed using the Kruskal-Wallis test. This statistical analysis is a nonparametric test which will look for 
significant differences between the racial groups on their responses to the survey instrument. This test is used to look for statistical significance when there are more than two groups in the independent variable on a dependent variable which is ordinal. A Mann-Whitney $\mathrm{U}$ test will also be used to analyze the survey responses. This test is used to determine significant differences between two groups in an independent variable when the dependent variable is ordinal (Laerd Statistics, 2015). The data from the interviews will be transposed and coded to look for common themes within the participant's responses. The use of the mixed methodology will contribute to a deeper understanding of the perceptions of these minority students. While the logistics of interviewing participants from many different regions will complicate the study, the use of Skype for interviews will make this process easier to complete. Interviews will also be coordinated with various regional and state conferences to increase the possibility of face-to-face interaction. To assure the validity of the subjects' responses to the interview questions, the researcher will share the transcript of the interview with the participant to verify that all responses were properly recorded.

\section{Definition of Key Terms}

Athletic Training: profession of allied healthcare professionals who are responsible for the care and prevention of injuries in an active patient population. This care includes injury recognition, treatment, injury rehabilitation, education, and prevention techniques for all injuries or illnesses which may occur as a result of activity or affect the patient's ability to participate in activity (Prentice, 2014). 
Athletic Training Education Program: an academic program at a college or university which leads to a major in athletic training. These programs are accredited and allow their graduates to sit for a national certification exam in athletic training (Prentice, 2014).

Diversity: the state of individuals within an organization being composed of differing characteristics. These characteristics include gender, race, ethnicity, age, socioeconomic status, religion, and sexual orientation (Jackson, 1992).

Racial Minority: any group of individuals who possess specific characteristics which differ from the larger number of individuals within a specific group. Examples of racial minorities in the United States are Blacks, Native Americans, Asian Americans, and Hawaiians (Schaeffer, n.d.).

Professional Socialization: the process of taking students and successfully transitioning them into practitioners. It also involves imparting upon the student the attitudes and behaviors that professionals need to be successful in their field (Mooney, 2007).

National Athletic Trainers' Association: the national organization representing the profession of athletic training. The NATA exists to promote the profession of athletic training and to protect the rights of its members (Prentice, 2014).

Board of Certification: the organization which administers the certification exam for athletic training. This organization is also responsible for renewing the certification of existing certified athletic trainers and collecting information on continuing education units (Prentice, 2014). 
Commission for the Accreditation of Athletic Training Education: the organization responsible for accrediting all athletic training education programs. This group determines the educational standards and competencies used by all programs (Prentice, 2014).

\section{Significance of the Study}

The primary significance of this study will be to determine factors which influence minority students' decisions to enroll in athletic training education programs. Directors of the programs can use this information to make changes in their recruitment policies that will increase their likelihood of obtaining minority applicants. In regard to the socialization of minority students into the profession, this information will need to be examined by the NATA and initiatives put into action that can correct the potential issues. These concepts can also be applied within my own athletic training education program to help with our low minority enrollment. Another significance of this study is the unbalanced minority representation between athletic trainers and the patient population which they serve. Current journals which primarily focus on athletic training related issues present minimal research on minority students and their levels of

enrollment. These journals also present little to no evidence of how these students perceives their education and socialization into the profession when compared to their White peers. If the issue of diversity within the profession of athletic training is not addressed, like it has been within our allied health care peers, then we risk becoming an irrelevant as a profession for the privileged.

\section{Summary}

Current literature shows that despite the trend of increased diversity in many other healthcare fields, athletic training has managed to keep its minority representation at the same 
level, or below, for the last eight years. Other professions, like nursing, have found innovative methods for increasing their recruitment of diverse students, and athletic training education programs can use a similar model. If any attempt to increase diversity in the field is going to be successful, it will be imperative that research look into the reasons minority athletic trainers were attracted to the profession, and how important their socialization into athletic training was to retention. 
Section Two:

Practitioner Setting for the Study 
Athletic Training as a field of study has emerged very quickly over the last fifty years. The National Athletic Trainers' Association created a curriculum model for athletic training programs in 1959 that prepared students to become athletic trainers and health and physical education teachers (Ebel, 1999). The intention of this type of curriculum program was to focus on the secondary schools as a primary place of employment. Despite having a curriculum model in place, it wasn't until 1970 that any athletic training majors were approved of by the National Athletic Trainers' Association. The first four universities to offer athletic training curriculums were Indiana State University, Lamar University, Mankato State University, and the University of New Mexico (Ebel, 1999). The curriculum model included the normal courses required to become health and physical education teachers along with additional courses in the care and prevention of injuries. These students also worked as interns in the athletic department alongside professionals who were employed as athletic trainers by these universities. It should be noted that these interns were often utilized by the athletic departments as employees and would often be solely responsible for the health care needs of athletes without any supervision.

In 1979, Central Michigan University announced the very first major in athletic training to allow for an academic specialization (Ebel, 1999). The National Athletic Trainers' Association decided that this was the direction that athletic training education should follow, and therefore stated that all athletic training programs must, by 1990, offer academic majors in athletic training. By the beginning of the 1990 academic year there were seventy-three universities offering athletic training as a major (Ebel, 1999). At this time, students at schools who did not offer athletic training as a major were still eligible to become athletic trainers as long as they completed a minimum of 1500 hours of internship experience under the supervision of an athletic trainer. This pathway to becoming an athletic trainer was phased out by 2004, when all 
athletic trainers were required to graduate from an accredited academic major in athletic training to become certified.

Throughout the rapidly changing evolution in the academic programs offering athletic training, the National Athletic Trainers' Association underwent its own changes in how these academic programs were overseen. The original curriculum was designed by a committee of the association, the Professional Education Committee. This committee took upon itself the task of visiting each athletic training program every five years and reporting on their adherence to the curriculum model and making recommendations for improvement. As the athletic training programs began their change to academic majors, the National Athletic Trainers' Association turned over the accreditation of these programs to the Committee for the Accreditation of Allied Health Education Programs. An independent organization tasked with accrediting academic majors in allied health care fields. The group within this organization responsible for athletic training accreditation was known as the Joint Review Committee on Athletic Training, and in 2006 this group became independent of the Commission on Accreditation of Allied Health Programs. This new independent accrediting body changed its name to the Commission for the Accreditation of Athletic Training Education and is the current accrediting body for all athletic training programs (Ebel, 1999).

The other primary component of becoming an athletic trainers, aside from graduating from an accredited athletic training education program, is the certification exam. The certification exam for athletic training was first offered in August of 1970 to twenty-eight candidates in Waco, TX (Lindquist et al., 2007). At the time, there were no states requiring an athletic trainer to be licensed or certified to practice, so the certification granted by the exam was not necessary but was a step toward legitimizing the profession as health care providers. Today, 
the certification exam is administered by the Board of Certification, and certification is required to obtain a license to practice athletic training in every state except for California (Lindquist et al., 2007).

Within the academic programs of athletic training the lack of diversity in athletic training students and certification candidates has been noted since very early on. In 1968, Jack Rockwell published an editorial in the Journal of Athletic Training which asked about the lack of Black athletic trainers despite the growing number of Black athletes in all levels of sport. The very rapid evolution of professional education did not include a concurrent increase in the diversity of athletic trainers in the profession. In 1997, almost thirty years after the Rockwell article, there were more than 21,000 certified athletic trainers, of which only 256 Blacks. That is $1.21 \%$ of the professionals in the field, and when all minority groups are included they still only made up $6.06 \%$ of all certified athletic trainers. As of February 2015, there were 1742 members of the National Athletic Trainers' Association reporting themselves as Black/Non-Hispanic, which accounts for only $3.7 \%$ of the entire membership. The total percentage of athletic trainers reporting themselves as White actually increased from $79.68 \%$ in 1997 to $80.98 \%$ in 2015 (Grantham, 2015). In contrast to these percentages, nursing reports a current population of Black professionals at $9.9 \%$. 
Section Three:

Scholarly Review for the Study 


\section{Introduction}

One of the most disturbing trends in health care professions is the slow growth of diverse practitioners graduating from schools in the United States. Growth of diversity in these fields has increased over the last ten years, but at a significantly slower rate than what has been shown to occur in most professions (Sullivan \& Mittman, 2010). Specifically, in the field of athletic training, levels of diversity have had no change over the last ten years with the number of athletic trainers reporting themselves as White, non-Hispanic remaining at 82 percent (Ethnic Diversity Advisory Committee, 2015). Despite this trend, the profession of athletic training has done very little to help increase these numbers aside from encouraging diverse recruitment practices at the university level.

Part of the difficulty of recruiting a diverse student population in athletic training education programs is the major shifts which have been occurring within the education of these professionals. In 1997, there were two routes to becoming an athletic trainer. The first was to attend a university with an internship program for students to work within while taking courses. The second route was to be formally enrolled in an approved curricular program which led towards certification. By 2004, all programs were required to become official degree programs, and an emphasis was placed on education over first-hand experience (Ebel, 1999). This has resulted in stagnant numbers of potential students who are unsure of entering an academic program that is undergoing major changes for accreditation. Most programs have been focused on increasing their overall numbers just to make their major relevant and profitable, and have allowed a focus on recruiting diverse students to fall to the wayside. This review will look at the field of athletic training as it compares to other health care professions. Theories will be explored 
which may potentially explain the lack of diversity within the profession, and the effects that this has on education of athletic trainers.

To accurately analyze the perceptions of minority students enrolled in athletic training education programs, and to attempt to remove my own biases as a White male in the profession of athletic training, I will attempt to view these issues through the lens of critical race theory. Critical race theory has four distinct concepts which one must address and understand when considering racial issues. The foremost concept which must be considered is the idea that racism is "normal, not aberrant, in American society" (Delgado \& Stefancic, 2012). The profession of athletic training must address and recognize the fact that there is an issue with inequity in its current educational model. Much like an addict, the profession must admit that there is a problem before a solution can be attempted. The next concept within critical race theory, is the idea that critical race theory relies heavily on storytelling examples to help clearly define racial issues (Ladson-Billings, 1998). This concept goes against traditional research, but fits in well with the qualitative research techniques that we have been learning throughout the program. To obtain these stories, the interviews of participants will become a crucial component of the dissertation.

Crenshaw (1988) gives us the third major concept of critical race theory. He presents the idea that racial issues cannot be addressed from within the current structure of most systems, because racial inequity is already inherent in the system. To make real change, one must radically overhaul the current structure of an organization (Crenshaw, 1988). If the NATA wants to correct the imbalance of minority representation in the profession, then it must completely rethink its approach to the recruitment of minority students.

The final concept of critical race theory is that most legislation instituted to benefit minorities has been more beneficial to Whites. Ladson-Billings (1998) gives the example that 
since the inception of affirmative action, White women have benefitted more than any other group. This goes back to the idea that athletic training must recognize that there is an issue, and then analyze their current diversity initiatives to determine who is truly benefiting from the policies.

When considering how new athletic trainers are brought into the profession, we look to the concept of professional socialization. Professional socialization has been little considered in the research for athletic training, but has been studied with the field of nursing extensively. Using nursing as a model for our profession, this research will attempt to make a connection between similar concepts of socialization within the literature and what is discovered during the data gathering. New nursing students have complained that policies are often set in stone and followed because that is what has always been done (Mooney, 2007). When we consider this through the lens of critical race theory we find that some of the policies which have kept minority students out of the profession may only be in place because that has been the traditional model. Mooney (2007) also reports that new nurses complained of feeling like they did not have a voice in their profession due to their lack of experience. Add the complication of being a minority student to this issue, and we can again see why many minorities may feel powerless within a profession predominated by Whites. Pitney et al. (2002) stated that the professional socialization of an athletic trainer to work in a NCAA Division I setting requires that the athletic trainer have gone through a graduate assistantship at a Division I school. Since it has already been discussed, that minority representation in post-graduate programs is lower than at the bachelor's level, it becomes apparent that this current model of professional socialization fails to take racial inequities into account. The ideas that athletic training at this level requires a great deal of time and dedication with very little reward financially or appreciation from the 
administration may also be a deterrent to a minority athletic trainer who may feel that they are already attempting overcome these issues (Pitney et al., 2002).

\section{Methods}

Research for this review was chosen based on multiple factors. The research could include both quantitative and qualitative analysis of the issue with an emphasis placed upon finding qualitative research. The methods which will be utilized in this research are a mixed methods approach, so any article which includes mixed methods research was considered for inclusion in the review. As stated previously, there is very little research available on the topic of diversity in the profession of athletic training, but there has been research done in related healthcare fields. A high value was placed on research that was done in medically related fields as opposed to other professions for their close similarity to the types of students drawn to these professions. Statistics for the profession of athletic training were accessed through the National Athletic Trainers' Association website which is only accessible to its members. Research which included the key terms of diversity, education, athletic training, and professional socialization were also given high consideration in being chosen for this review. All articles were found through EBSCO Host, ProQuest Central, PubMed, and Medline research databases.

Barfield et al. (2012) utilized data from a larger study which looked at factors which influence a student's decision to enroll in a specific major and the factors which are barriers to enrollment. The tools used for this study were the Scale for Allied Health Enrollment Decision (SAHED) and the Scale for Allied Health Enrollment Barrier (SAHEB). Both of these scales had been previously assessed for their validity and reliability. Theses survey tools were distributed to students in multiple majors at ten Midwestern universities, and those students who identified themselves as majoring in a kinesiology related field were sampled for this study (Barfield et al., 
2012). Kinesiology related fields include athletic training which is why this study is significant for inclusion within the review. The SAHED includes the following factors as influencing a student's enrollment; personal influences, social influences, academic preparation, career opportunity, individual aspiration, and physical self-efficacy (Barfield et al., 2012). The factors which act as barriers to enrollment as presented in the SAHEB are; social influence, experiential opportunity, academic preparation, physical self-efficacy, and self-management. The students surveyed in this research were all currently enrolled in kinesiology related fields and all ten universities returned completed surveys.

Hung et al. (2007) looked into the issue of diversity and cultural climate at medical schools and the perspectives of the students enrolled in these programs. This particular study is important for inclusion in this review of literature due to its similarity to the current research. The researchers in this study utilized a mixed methods approach which consisted of surveys of all students within the university. The survey was developed by the researchers in this study and therefore not validated before its use. They followed this step with a series of four focus groups of ten students each consisting of representatives from the various ethnic and racial groups found at the university. The data from the surveys and the responses during the focus groups were then analyzed to identify themes related to diversity and the cultural climate at the institution (Hung et al., 2007). The primary weakness of this study is that it was focused on only one university. Racial diversity issues and the cultural climate of any organization is influenced by population density, geographical location, and historical influences. An attempt to extrapolate this research into the entire education system would be inaccurate, but it does present a framework from which to build further research. 
Mazerolle et al. (2012) chose to do an exclusively qualitative study on the influences that affect a student's career decisions upon graduation. The reasoning given for choosing a qualitative only approach in this study was "that qualitative methods are appropriate for understanding meanings: understanding contexts in which participants received education and work, understanding thought processes rather than outcomes, and identifying critical influences on attitudes and behaviors" (Mazerolle et al., 2012, p. 680). Qualitative research does give a researcher the ability to easily analyze results for comparison and presents clear outcomes. What it fails to do in some instances, is to clearly identify the actual influence that a factor has on an individual's decision or the magnitude of those influences. Surveys force participants to limit their responses to specific factors identified by the researchers. The importance of this article to the current research is the consideration of those factors which influence a student's decision to remain in the profession. This information will be discussed with current participants to determine if socialization into the profession is a factor on their desire to remain in athletic training upon graduation. The other weakness of this study was the very low response rate from those surveyed. The authors reported a response rate of only 22 participants $(n=22)$ from 13 different athletic training education programs of the 75 programs which were sent surveys. They also reported an overwhelming response from female students compared to males, which may create a gender bias within the results (Mazerolle et al., 2012). This low response rate may be indicative of the type of response rate which I may receive from respondents, and steps to increase this rate will need to be considered for the current research.

Another study which can be used as a framework for the current research was conducted by Hoodless (2004) with students in an initial teacher preparation program. This study utilized quantitative methods by conducting focus group interviews with ethnic and racially diverse 
students during their first and third years in the teacher preparation program. One key component of these focus group interviews, as signified by the author, was that they were facilitated by someone of an ethnic minority group (Hoodless, 2004). The justification given by the author was that, "The resulting comments, therefore, have much greater authenticity and honesty than if the discussions had been held with White researchers" (Hoodless, 2004, p. 35). Consideration of this must be given when interviews and focus groups are utilized, and if the responses which I receive will be genuine based upon my identification as a White male. This research conducted small focus group interviews which consisted of the same questions for each group, and responses were recorded and transcribed. The responses were then categorized and grouped according to the themes identified (Hoodless, 2004).

Melillo et al. (2013) focused their research on determining the effectiveness of their recruiting practices for minority students in a nursing program. This study looked at efforts which had already been implemented to determine the program's effectiveness. A survey designed by the researchers was distributed to students at both the middle school and high school in areas identified as underprivileged with high minority representation. These surveys included questions about what nursing job tasks, requirements to become a nurse, and who can become a nurse. These surveys were given to students at the schools over a period of three years. During this time, minority nursing recruiters implemented nursing outreach and education at the schools. Responses on the survey were looked at over the three-year period, and minority enrollment at the nursing school was tracked during these same periods of time (Melillo, 2013).

\section{Findings}

As many of the studies used in this research for review are of various healthcare fields and differing methods were utilized, it becomes difficult to directly compare their results. This 
review will address each of the numerous studies discussed and attempt to connect the various themes found throughout. Barfield et al. (2012) reports in their study, that in all categories of both the SAHED and SAHEB, African-American students reported higher scores when compared to their Caucasian peers. The researchers state that this result means that for AfricanAmerican students there were more influences and barriers to their decision to enroll in a kinesiology related major (Barfield et al., 2012, p. 166). This result is significant to the current research, because it is paramount that the factors which influence and deter minority students from enrolling in athletic training programs is one of the primary research questions. This study gives the means of possibly predicting results which can then be compared. Barfield reports that the most significant influences for African-American students were personal influence, career opportunity, and physical self-efficacy. The most significant barriers identified for these students were social influence, experiential opportunity, academic preparation, and physical self-efficacy (Barfield et al., 2012).

In the research conducted by Hung et al. (2007), there were 216 responses to the survey. Of those participants, $25 \%$ reported themselves as being non-White. The authors reported that $84 \%$ of participants reported that they felt that having a diverse student body was important to their overall learning experience (Hung et al., 2007). They also reported that $56 \%$ of students felt that a lack of diversity in the student body would weaken the learning experience (Hung et al., 2007). Another interesting result of study is seen when comparing the responses of White students on specific questions when compared to their non-White peers. White students reported lower scores when asked if they felt that the school made it safe to discuss issues of race and culture, and they also reported significantly lower scores when asked about the importance of considering race and culture when treating their patients. These results highlight the importance 
of considering the responses of White participants when making comparisons of their survey responses in the current research. It will be necessary to show a significant difference between White and non-White responses before any conclusions can be made about the perceptions of minority students in regard to athletic training. Without a significant difference, it cannot be shown that race or culture plays a role in their decision to enroll in to the athletic training degree program.

Mazerolle et al. (2012) reported that their research determined three specific factors which positively influence a student to remain in the profession of athletic training following graduation. These three factors were marketability, faculty support, and professional growth (Mazerolle et al., 2012). The authors also identified five factors which influenced a student's decision to leave the profession; athletic training as a stepping stone to another profession, shift of interest away from athletic training, lack of respect for athletic training, compensation, and time commitment Mazerolle et al., 2012). The current research is looking at socialization of minority students into the profession as a factor which will influence their decision to remain in the profession. Mazerolle et al. (2012) reports that those students who transition into graduate assistant positions were more likely to stay in the profession. As the profession transitions to an entry-level master's degree, it will be important to conduct further research to determine if this increase in the required amount of education will become a factor to deter students from the profession.

Though not related directly to a health care profession, the results from the study conducted by Hoodless (2004) can be compared with issues found in any academic preparation program. Isolation was reported as one of the main themes of the participant responses. The participants reported feelings of isolation due to low minority enrollment within their courses, 
low minority representation among faculty, and low minority representation at their assigned schools (Hoodless, 2004). This is a theme which must be taken into consideration within athletic training education programs. How do we limit feelings of isolation for minority students when the population of our regions is overwhelmingly White? Difference was listed as a second major theme in the study conducted by Hoodless (2004), with both positive and negative experiences being reported. Some students felt that their religious and cultural needs were not being considered by the program. Other students reported that their differences resulted in a positive experience during their students teaching, because the students were interested in learning about their culture (Hoodless, 2004). Support was a third theme identified in this study, and this theme related mainly to where the support came from for the student. White students reported that they felt their faculty gave them adequate academic support, while minority students felt that their peers provided them with the greatest level of support (Hoodless, 2004). A final theme identified by Hoodless (2004) that relates to the current research is that of relationships. The relationship between the students and their mentor and between the students and their peers are important to the success of a student within their program of study.

In the results reported by Melillo et al. (2013), the researchers focused much of their data gathering on the effectiveness of their recruiting efforts by tracking the increases in minority enrollment in the nursing program. The overall effect of the recruitment efforts was a $3.02 \%$ increase in the number of minority enrollments over the three-year period. They also reported that the retention rate of minority students from freshman to sophomore years went from $77 \%$ at the beginning of the study to $92 \%$ at the end of the three-year period (Melillo et al., 2013). The author directly gives credit for these increases to the efforts of the recruiting program, but nowhere within the article is a significance number presented. This would bring into question the 
validity of the authors' claims, and further research would need to be conducted to show a cause and effect relationship. No external factors or data were considered for this study. For example, what were the minority enrollment numbers for other nursing programs during that same period?

\section{Conclusions}

The review of these numerous studies is important for providing a framework of how both quantitative and qualitative methods will be implemented within the current research. These studies also provided valuable examples of what weakness can appear within the research, and give a clear picture of how to avoid those same pitfalls. It is clear that to adequately answer the research questions it will be necessary to have both types of data. The quantitative data will help develop a means of comparing the various responses of the minority students with their White peers to determine if there are any significant differences in their perceptions. Care must be taken when developing the survey instruments to ensure that they are valid and reliable tools, and I am considering utilizing survey tools which have been previously validated for this research. The participant responses for this study will also need to be high enough to show a significant impact for the profession. I will be utilizing my resources as an educator to contact as many programs as possible to gather student responses. Based on geographical and population differences, care will need to be given to ensure that the participant samples give an accurate representation of the profession.

It has been shown in the research that diversity within the learning environment is an important factor for increasing students' success (Hung et al, 2007; Melillo et al., 2013). As the low diversity enrollment in athletic training is studied, this factor will need to be researched. This is where the perceptions of the individual minority students will become important. During the proposed interviews, questions will need to be designed which address their feelings toward 
learning in a diverse classroom versus a low minority class environment. As discussed by Hoodless (2004), the ethnicity and race of the individual conducting the interview must be accounted for when considering the possible biases that may come into the conclusions drawn from the interviews. The data gathered during the focus group interviews will help the reader to understand the meaning behind the responses reported on the survey tools. This will give a richer meaning to the data gathered in the study and allow the reader to understand why the various influences and barriers were more important to the minority student than to their White peers.

As the numbers of minority students increase within healthcare programs it will become even more important to identify to specific reasons for those increases (Melillo et al., 2013). Broader trends of minority enrollment within all of healthcare professions need to be considered when specifically comparing the profession of athletic training. It has already been shown that the trend of increasing minority enrollment for the professions of nursing and physicians has gradually been increasing, while athletic training has remained relatively stagnant over the last eight years (National Athletic Trainers' Association, 2015; Melillo et al., 2013; Hung et al. 2007). What factors are specific to the profession of athletic training which led to this resulting stagnancy in minority enrollment?

With very little research on minority students in the field of athletic training having been conducted, this research takes an important look into the barriers and influences experienced by these students. Athletic training education programs that are looking to increase their enrollment of minority students have very limited access to any type of significant data showing these influences and barriers. Without this information, it becomes difficult to form a plan of action to address the problem and find a solution which benefits both program and the students. This research will give these professionals a foundation of perspectives and data on which to build 
their own programs. Patients will benefit from the increase in the diversity of practitioners in the field, and the profession will benefit financially from the improvement in patient outcomes. Further research will be needed to address how the recent change to an entry-level master's degree requirement will affect the minority applicants, but this is outside of the scope of the current research as it has only been implemented in very few programs at the time of this study. 
Section Four:

Contribution to Practice 


\section{Plan for Dissemination}

This research is designed to help faculty of athletic training education programs make better decisions regarding recruiting of minority students. The goal is to create a deeper of understanding of the barriers faced by these students, so that efforts can be made to remove some of these factors. The professional organizations in athletic training offer several resources to disseminate information to their members. The NATA publishes a monthly magazine called the NATA news, which includes articles to help the practitioner. The NATA news is an excellent resource for practitioners because it presents material in an easy to read and understand format that involves less technical reading than a peer reviewed journal. The NATA also sponsors a biannual conference for educators known as the Athletic Training Educators' Conference. This is an excellent resource to directly interact and present my findings to the practitioners who would most benefit from the information.

\section{Type of Document and Rationale}

This research would most easily be presented to practitioners in the form of a policy analysis report and brief. The presentation of data in regard to positive and negative influences of minority students when choosing athletic training as an academic major can directly impact the current policies of a university's program in regards to recruiting these students. Discussion in a conference setting of these policies will allow the practitioner a deeper understanding of my results. Discussion will also allow ideas to be shared between practitioners after they have been presented with the information. 
Positive and negative influences perceived by minority students

toward a career in athletic training

\section{What is the Problem?}

The current policy in athletic training is to approach all future students in the profession in the exact same manner with no consideration for outside factors which may act as barriers. The lack of diversity in the field of athletic training is a pressing concern for the profession, we begin to see other professions like physical therapy and nursing significantly increase their diversity of practitioners. This lack of minority representation becomes even more disconcerting as professional education begins its transition to a master's degree as the requirement for entrylevel athletic trainers. Research has shown a decrease in the number of minorities in higher levels of education, yet athletic training is choosing to go that direction with little thought for how this change will affect the diversity issue.

The profession still adheres to an older model of apprenticeship-like experience that deters students from holding a job to help pay for their schooling. This limits the students from low income families from choosing this major because of its extreme time requirements. There is also the issue of admissions counselors and academic advisors not fully understanding the educational programs and profession, so that only certain students who already express interest in the field are guided toward the major. What about the student who has never had any previous exposure to the profession? These individuals need to be made aware of the choices available to them. This research shows a grave concern with how influential counselors and advisors at the university are in guiding students, and White students reported significantly higher numbers when asked if they were positively influenced by these people. It is my recommendation that 
programs educate their university's advising and admissions staff of the specifics of athletic training. It is also recommended that athletic training education programs make recruiting a more diverse student population a program goal which they should regularly measure and assess to determine their effectiveness as required by accreditation.

\section{What does research say?}

One of the most disturbing trends in health care professions is the slow growth of diverse practitioners graduating from schools in the United States. Growth of diversity in these fields has increased over the last ten years, but at a significantly slower rate than what has been shown to occur in most professions (Sullivan \& Mittman, 2010). Specifically, in the field of athletic training, levels of diversity have had no change over the last ten years with the number of athletic trainers reporting themselves as white, non-Hispanic remaining at 82 percent (Ethnic Diversity Advisory Committee, 2010). Despite this trend, the profession of athletic training has done very little to help increase the number of diverse individuals entering the profession aside from encouraging diverse recruitment practices at the university level.

It is difficult to critique current policy regarding diversity in the field of athletic training, because of the lack of any specific policy to increase the levels of diverse practitioners. Levels of White professionals have stayed around eighty-five percent over the last ten years, and despite some minor attempts at forming an Ethnic Diversity Advancement Committee to research the issue, the NATA has not put forth any type of policy recommendation. Some of the individual programs have policies related to non-discrimination based upon race or ethnicity, but none of them have a policy of actively recruiting students. 
Looking at athletic training education programs is important for ascertaining what the root causes are for a lack of diversity in the profession. This is the entry point for any individual interested in becoming an athletic trainer, which means that the education programs are the essential point at which minority students decide to join the profession. What issues exist within these programs which potentially lead to a minority student not choosing this degree program? What factors play a role in the retention of minority students once they have enrolled in an athletic training program? As we look at finding the answers to these questions, we must consider how the white students enrolled in these programs view these same factors. We can then determine if race plays a role in enrollment or retention, or if this is a broader student issue.

To that end, research has been conducted about these topics with athletic training students who are currently enrolled in accredited athletic training programs in the state of Missouri. The research was conducted using both surveys and interviews with these students and there were some significant factors identified. The research showed a significant difference in the level of importance that White and minority students give to a college counselor. The data also showed a significant difference in the influence that the two groups put on the desire to affect the health of minority patients. The final piece of what this research demonstrated was a significant difference in the attitudes of faculty toward race and culture made between the White and minority groups.

This research has also shown that minority students view having few role models of their own race in the profession as being a barrier to choosing this major. If a student has never been exposed to the profession, or seen anyone like themselves doing it, why would they think it was an option? This means that the NATA and the individual programs must make a better effort to educate students from predominantly minority schools about the athletic training profession. There is already a policy effort in the NATA to increase the number of athletic trainers in the 
secondary school setting. This policy would be beneficial because it will expose more students to the profession and let them see what an athletic trainer does.

The other important policy issue which needs to be addressed is the college counselor and academic advisor policies at the individual institutions. These individuals are vital to guiding our students toward the profession, and many have little to contact with faculty or staff within the athletic training program. Imagine that when guiding students toward a profession which you know nothing about, how you would perceive the type of student who would be successful? I would look at who is currently in the field, and when you look at athletic training that is primarily White people. The average student in our programs is White, from a middle to upperclass economic background, and has had some exposure to the profession through their own high school. It would only be natural to assume that this is the type of student who would be interested in this program. The current policy of having the athletic training program and advising operating apart from each other is not working.

\section{Policy Alternative 1}

The first recommendation for policy change is for each program to add a program goal to their current list of goals which specifically calls for increasing the diversity of the students in their program. The accrediting body already requires that programs report their goals, and how those goals are being measured and assessed on an annual basis. This addition of a new diversity goal would help to hold the program accountable for their efforts to increase diversity. The annual review process would result in the creation of action plans for programs who do not report meeting their goals. These action plans will help guide programs in their efforts to recruit minority students, and even if the goals are not being met, the program can show progress. 
Consideration of the equity of this policy must be given thought before its implementation. It is important that the program design their goal as a desire to increase their diversity of students and not as a quota system. Setting specific numbers for their minority enrollment would lead to some questionable ethical and legal issues when looking at acceptance rates for the various racial groups. The intention of this policy is to make potential applicants aware that your program considers diversity as an important part of its overall mission. This has the potential to attract minority students who are unsure if this profession would be right for them.

\section{Policy Alternative 2}

The second recommendation for policy change is for the academic programs to have a specific athletic training counselor or advisor assigned to them. This individual should be well educated on the profession of athletic training and its educational requirements. This advisor can become the point of contact for the program and act as a liaison between the two departments. The efforts of this advisor can be directly tracked through the first policy recommendation of the additional program goal. They should be included in program meetings about recruitment and retention to allow them to receive input from program faculty. This individual would also be responsible for educating the admissions department about the profession and making sure that all students are given accurate information about the profession.

Having a counselor assigned directly to the program may not be cost effective for some programs. At many institutions, the academic counselors and advisors work with several different programs, so this policy could potentially create some issues of fairness amongst the other majors. The key point to this policy is that there should be one "go to" person within advising who can provide accurate information about your program to potential students. 


\section{Summary}

It is recommended that both policy alternatives be attempted to help programs increase their minority student enrollment. Both alternatives can be instituted with little financial cost to the programs. The research supports that students are affected by the attitudes of the faculty and staff toward diversity. By creating the goal of increasing diversity, it will show students that your program considers this issue important, and gives a picture of your program's attitudes toward diversity. Getting students directed to your program is alo a very important step which shows your commitment to diversity. This is where the college counselors and advisors play a key role in the program's enrollment. It is difficult to say at this time how the upcoming change to an entry-level master's degree will change the levels of minority student enrollment, but these policies may help the program to be proactive in their goals. 
Section Five:

Contribution to Scholarship 


\section{Target Journal and Rationale}

The most appropriate journal to present this research in would be the Athletic Training Education Journal. This is the only peer reviewed journal dedicated to the dissemination of research related to athletic training education. The journal is an open access journal which allows for free access, download, and printing of articles for all users. The journal is managed by the NATA's scientific publications office (National Athletic Trainers' Association, 2010). I have also considered submitting to the Journal of Athletic Training, which is the primary peer reviewed resource related to athletic training research. The content presented in the Journal of Athletic Training very rarely focuses on research of education policy, but instead focuses on clinical treatments and injury case studies.

\section{Outline of Proposed Content}

Based upon the Athletic Training Education Journal Authors Guide, the outline of the research must be presented in the following manner. The journal considers this type of research to be a survey article. Survey articles must include sections on context, objective, design, setting, participants, data collection and analysis, results, conclusion(s), and key words. All research must be submitted in the American Medical Association (AMA) style according to its guidelines published in the AMA Manual of Style, $10^{\text {th }}$ edition (National Athletic Trainers' Association, 2010). 
Positive and negative influences perceived by minority students toward a career in athletic training.

Stephen Nickell, MA, ATC

Southeast Missouri State University

One University Plaza, MS7650

Cape Girardeau, MO 63701

937-631-4660

snickell@semo.edu 
Positive and negative influences perceived by minority students

toward a career in athletic training.

\begin{abstract}
Objective: The lack of diversity in the profession of athletic training is a concern as other healthcare professions increase the number of minorities in their fields. This research explores the influences and barriers that students perceive exist for choosing this profession and how race or ethnicity plays a role. Design and Setting: The study is a mixed methods research which is using a survey and interviews to provide data. The study is specifically looking at professional athletic training programs in the state of Missouri. Subjects: Participants were undergraduate students currently enrolled in an accredited athletic training program in the State of Missouri. Measurements: Surveys were distributed and collected via Qualtrics and results were analyzed through a Kruskall-Wallis test and a Mann-Whitney U test. Interviews were transcribed and coded to determine common themes. Results: Significant differences were found between the responses of White and minority students on survey items related to college advisors, desire to help diverse patient populations, and a lack of role models in the profession. Conclusions: Policies related to the advising of potential athletic training students must be assessed to look at possible racial bias, and efforts to recruit diverse student populations should be a priority for athletic training education programs.
\end{abstract}

Key Words: Athletic Training Education, Professional Socialization, Critical Race Theory 


\section{INTRODUCTION}

One of the most disturbing trends in health care professions is the slow growth of diverse practitioners graduating from schools in the United States. Growth of diversity in these fields has increased over the last ten years, but at a significantly slower rate than what has been shown to

occur in most professions. ${ }^{15}$ Specifically, in the field of athletic training, levels of diversity have had no change over the last ten years with the number of athletic trainers reporting themselves as White, non-Hispanic remaining at 82 percent. ${ }^{4}$ Despite this trend, the profession of athletic training has done very little to help increase the number of diverse individuals entering the profession aside from encouraging diverse recruitment practices at the university level.

Looking at athletic training education programs is important for ascertaining what the root causes are for a lack of diversity in the profession. This is the entry point for any individual interested in becoming an athletic trainer, which means that the education programs are the essential point at which minority students decide to join the profession. What issues exist within these programs which potentially lead to a minority student not choosing this degree program? What factors play a role in the retention of minority students once they have enrolled in an athletic training program? As we look at finding the answers to these questions, we must consider how the White students enrolled in these programs view these same factors. We can then determine if race plays a role in enrollment and retention, or if race is a broader student issue. Through a mixed methods study, this research will not only look at the differences between both groups, but will also determine underlying reasons for decisions by individual minority participants. 


\section{METHODS}

Setting. The setting for this mixed methods study was isolated to undergraduate accredited athletic training education programs in the state of Missouri. Certification in athletic training is accomplished through completion of an accredited athletic training education program and the successful passing of the Board of Certification exam. There are currently ten bachelor level programs throughout the state of Missouri. The setting chosen for this research was selected due to restrictions on travel for the researcher and availability of subjects.

Participants. The participants in this study are all students currently enrolled in an undergraduate athletic training education program at the bachelor's level at the universities in the state of Missouri which offer this program. The students' participation in the research was voluntary, and an informed consent was obtained from each participant. A pilot study was completed with students who are enrolled in the athletic training education program at Southeast Missouri State University. These students were not included in the final research data to avoid any conflict of interest with the researcher who is the director of the Southeast Missouri State University athletic training education program.

Data Collection Tools. The initial portion of the data collection was completed with a survey tool. The survey tool was distributed to each participant along with the informed consent for the study. The survey tools this research utilized were a combination of the Scale for Allied Health Enrollment Decision (SAHED) and the Scale for Allied Health Enrollment Barrier (SAHEB). Refer to Appendix A for a detailed description of the questions asked in the SAHED and Appendix B for the SAHEB. Both the SAHED and the SAHEB have undergone extensive analyses for their validity. ${ }^{1}$ The participants were also asked for demographic information regarding their race. This information is vital for comparison of survey answers to look for any 
significant differences in the responses of minority students with their White peers. Once the initial data collection gathering portion had been completed, further data gathering was accomplished through semi-structured interviews (see Appendix C) with a purposeful sample of five to seven minority participants from universities surveyed in the state of Missouri. The participants interviewed were selected based upon their availability and willingness to speak with the researcher. A cross section of institutions is the goal for this portion of the data gathering process, but the availability of the participants and their location in relationship to the researcher had to be considered.

Data Analysis. The data from the survey responses was compiled and analyzed through comparative statistics. Responses to the survey responses were analyzed using the KruskalWallis test. This statistical analysis is a nonparametric test which looks for significant differences between the racial groups on their responses to the survey instrument. This test is used to look for statistical significance when there are more than two groups in the independent variable on a dependent variable which is ordinal. ${ }^{7}$ A Mann-Whitney $\mathrm{U}$ test was also used to analyze the survey responses. This test determines significant differences between two groups in an independent variable when the dependent variable is ordinal. ${ }^{7}$ The data from the interviews was transposed and coded to look for common themes within the participant's responses. The use of the mixed methodology contributed to a deeper understanding of the perceptions of these minority students. While the logistics of interviewing participants from many different regions was complicate the study, the use of Skype for interviews made this process easier to complete. Interviews were also coordinated with various regional and state conferences to increase the possibility of face-to-face interaction. To assure the validity of the subjects' responses to the interview questions, the researcher shared the transcript of the interview with the participant to verify that all responses were properly recorded. 


\section{RESULTS}

\section{Quantitative}

A Kruskall-Wallis test was conducted to determine if there were differences in the SAHED and SAHEB scores between groups that differed based upon how the participants selfidentified their race or ethnicity: the "White" $(n=33)$, "Black or African-American" $(n=4)$, “Asian" $(n=2)$, "Native Hawaiian or Pacific Islander" $(n=1)$, "Hispanic or Latino" $(n=1)$ race or ethnicity groups. Distributions of the SAHED and the SAHEB were not similar for all groups, as assessed by visual inspection of a boxplot. The scores for the SAHEB survey item "Social Influences-college counselor" were significantly different between the various race or ethnicity groups, $X^{2}(3)=9.609, p=.048$. Subsequently, pairwise comparisons were performed using Dunn's procedure with a Bonferroni correction for multiple comparisons. Adjusted $p$-values are presented. This post hoc analysis revealed statistically significant differences in SAHEB scores for the survey item of "Social Influences-college counselor" between the White (mean rank = 22.85) and Black or African-American (mean rank =9.00) $(p=.014)$ race or ethnicity groups, but not between any other group combinations.

The scores for the SAHEB survey item "Social Influences-attitudes of faculty towards race and culture" were significantly different between the various race or ethnicity groups, $X^{2}(3)$ $=9.647, p=.047$. Subsequently, pairwise comparisons were performed using Dunn's procedure with a Bonferroni correction for multiple comparisons. Adjusted $p$-values are presented. This post hoc analysis revealed statistically significant differences in SAHEB scores for the survey item of "Social Influences-attitudes of faculty towards race and culture" between the White $($ mean rank $=22.73)$ and Black or African-American $($ mean rank $=6.75)(p=.003)$ race or ethnicity groups, but not between any other group combinations. 
A Mann-Whitney $U$ test was run to determine if there were significant differences in the SAHED and SAHEB scores between "White" and "Minority" as selected by the research participants. For this test, the participants who self-identified as being in the "Black or AfricanAmerican"," Asian", "Native Hawaiian or Pacific Islander", or "Hispanic or Latino" groups were combined as "Minority". Distributions of the SAHED and SAHEB were not similar, as assessed by visual inspection. The scores (Figure 1) for the survey item "Individual Aspirations - Desire to affect the health of minorities" for Whites (mean rank $=23.12$ ) were significantly higher than for Minorities (mean rank $=12.25$ ), $U=202, z=2.414, p=.020$. The scores (Figure 2 ) for the survey item "Social Influence - A college counselor" for Whites (mean rank $=22.85$ ) were significantly higher than for Minorities (mean rank $=13.38$ ), $U=193, z=2.256, p=.045$. The scores (Figure 3) for the survey item "Experiential Opportunity - Availability of role models in the field of same ethnicity" for Whites (mean rank =22.89) were significantly higher than for Minorities (mean rank $=13.19), U=194.5, z=2.140, p=.038$.

After completion of the Kruskall-Wallis test and the Mann-Whitney U test on the survey data, there are some significant factors identified. Both statistical tests show a significant difference in the level of importance that White and minority students give to a college counselor. The data is also showing a significant difference in the influence that the two groups put on the desire to affect the health of minority patients. The final piece of what this data is showing a significant difference in the attitudes of faculty toward race and culture made between the White and minority groups.

\section{Qualitative}

Eight interviews were conducted using a combination of in-person interviews and Facetime for interviews which had to be performed at a distance. Once interviews were 
completed, each of the participants' responses to the interview protocol questions were transcribed into one continuous document to assist with the coding of responses. First level coding was completed using both attribute coding and structural coding. Attribute coding is a method of labeling each participant using a standard method to help organize the responses and put them into context for further analysis. ${ }^{13}$ Using this method of first level coding the participants were labeled according to their name and assigned alias, race or ethnicity, gender, and format of interview. The coding of these participants can be found in Table 2.

Structural coding is described by Saldana ${ }^{13}$ as a method through which conceptual phrases are used to describe responses to specific protocol questions. Responses to the interview questions were given structural coding based upon how the participants answered each question. For example, the structural code assigned to the interview question, "How did the diversity of the athletic training program at your institution affect your decision to enroll in this major?" was "No influence on decision." All first level coding was kept within the original transcripts of the interviews to allow for ease of analysis upon further coding.

Second level pattern coding was then applied to the interview responses. Pattern coding is when the input from the participants is looked at for patterns and common themes, and then those themes and patterns are assigned a descriptive label. ${ }^{13}$ Pattern coding of the participant responses in this research was grouped into four specific themes. The themes identified were "Diversity not a factor", "Lack of diverse role models", "Barriers for minorities", and "Salary expectations."

Diversity not a factor. When the responses from each participant were analyzed to determine responses to the question of diversity playing a role in their decision to enter the profession, none of the participants indicated that it was a factor. Participant 1, a Black or 
African-American female, stated, “Actually I didn't even think about any of that. It was just something that I wanted to do, so I just did it. I didn't even think about diversity.” Similar responses were obtained from all participants on this topic. Participant 6, an Asian female, went into greater depth with her explanation of why diversity did not factor into her decision. She stated that she was one of the only minority students in her high school, and that a lack of diversity in her schooling was normal for her.

Lack of diverse role models. In analyzing input on the lack of role models in the profession of athletic training who are of the same ethnicity, all participants indicated that they had never been exposed to any other race of professional athletic trainer but White. This resulted in responses from the White participants that they had numerous role models. Participant 5, a White male, responded by saying, "I would say I have had a lot of exposure, but it did not affect my career plans or anything." Each minority participant indicated that the lack of role models of the same race or ethnicity did not factor into their decision to choose athletic training as a major.

Barriers for minorities. The analysis of the question of perceived barriers for minorities to enter the field of athletic training resulted in two distinct subcategories of answers. Many participants indicated that they did not feel that there was any specific barrier to a minority entering the profession as compared to their White peers. Both Participant 2 and Participant 6, who identified themselves as Asian, discussed barriers that they perceived to exist for them to enter the profession of athletic training. Both participants indicated that their physical size was a perceived barrier to being successful. Participant 2 stated, "My parents weren't okay with it because it's not considered a doctor or a nurse, and they did not think it was a good idea because of my size." Participant 6 stated, "I work with a baseball team and there's like thirty-five guys who's over six foot and I'm only five foot so that's an issue." Participant 2 also discussed the 
perception that the difficulty of pronouncing her name and its obvious Asian origin would result in her application not being considered by potential employers.

Salary Expectations. Second level pattern coding also resulted in a common theme of potential low salary playing a factor in the participants' decision to enter the field of athletic training. All participants but Participant 2 indicated that salary had some influence on their decision. Participant 3, a White male, and Participant 8, a Black or African-American female, both stated that they intended to combine their athletic training degree with an additional degree which would lead to the potential of a higher salary. 


\section{DISCUSSION}

To accurately analyze the perceptions of minority students enrolled in athletic training education programs, and to attempt to remove my own biases as a White male in the profession of athletic training, this study viewed these issues through the lens of critical race theory. Critical race theory has four distinct concepts which one must address and understand when considering racial issues. The first concept which must be considered is the idea that racism is "normal, not aberrant, in American society." ${ }^{3}$ The profession of athletic training must address and recognize the fact that there is an issue with inequity in its current educational model.

The second concept within critical race theory, is the idea that critical race theory relies heavily on storytelling examples to help clearly define racial issues. ${ }^{6}$ To obtain these stories, the interviews of participants is a crucial component of the research. In this research, it was noted through interviews that money played a critical role in the decision making of minority students. This information was not found in the survey data, but was reported by almost every minority participant that was interviewed. Many of them stated that they were concerned about their earning potential once they left school. There was also concern with the amount of clinical work required in the major, leaving little time for a part-time job to offset the cost of school. This is a clear example of why storytelling is an important part of critical race theory, because it helps us dig deeper into what the participants are thinking and feeling.

Crenshaw $^{2}$ gives us the third major concept of critical race theory. He presents the idea that racial issues cannot be addressed from within the current structure of most systems, because racial inequity is already inherent in the system. To make real change, one must radically

overhaul the current structure of an organization. ${ }^{2}$ If the NATA wants to correct the imbalance of 
minority representation in the profession, then it must completely rethink its approach to the recruitment of minority students.

The fourth and final concept of critical race theory is that most legislation instituted to benefit minorities has been more beneficial to Whites. Ladson-Billings ${ }^{6}$ gives the example that since the inception of affirmative action, White women have benefitted more than any other group. White women have seen over $15 \%$ increase in employment as opposed to only a $2 \%$ increase in employment of minorities in government positions. This goes back to the idea that athletic training must recognize that there is an issue, and then analyze their current diversity initiatives to determine who is truly benefiting from the policies.

Research question one (RQ1): What are minority students' perceptions of their socialization into the profession of athletic training?

Research question 2 (RQ2): What are White, non-Hispanic students' perceptions of their socialization into the profession of athletic training?

The study showed that minority students did not perceive their socialization into the profession of athletic training as being any different than that of their White peers. During the interviews, all participants responded that they felt their academic program was preparing them well to transition into professional practice by allowing them to learn in a hands-on real-world environment. They also indicated that each of their programs were instilling professional behaviors in them to allow for an easier transition.

Professional socialization has been little considered in the research for athletic training, but has been extensively studied with the field of nursing. ${ }^{5,9,10,14,16}$ Using nursing as a model, this research attempts to make a connection between similar concepts of socialization within the 
literature and what is discovered during the data gathering. New nursing students have complained that policies are often set in stone and followed because that is what has always been done. ${ }^{10}$ When we consider this through the lens of critical race theory we find that some of the policies which have kept minority students out of the profession may only be in place because that has been the traditional model. An example of a traditional policy for athletic training education is that students are required to obtain an unusually high number of clinical contact hours outside of class. These clinical hours are linked to a grade in one of their academic courses, and they are often only given one credit hour for their clinical experience. This clinical experience often gets in the way of family and work obligations. Interview responses did reveal that some participants considered time management as an important part of their success in their major because of their need to work to pay for tuition. The need of students to work to pay for their tuition must be considered in the fourth concept of critical race theory. ${ }^{2}$ The current policy of requiring such a high number of clinical experience hours benefit students who do not need additional support to maintain their expenses. The intention of this policy is to provide hands-on, immersive learning, but the unintentional result is that it is a barrier for low income students, many of which are minorities.

Pitney et al. ${ }^{12}$ stated that the professional socialization of an athletic trainer to work in a NCAA Division I setting requires that the athletic trainer have gone through a graduate assistantship at a Division I school. Since it has already been discussed, that minority's representation in post-graduate programs is lower than at the bachelor's level, it becomes apparent that this current model of professional socialization fails to take racial inequities into account. The idea that athletic training at this level requires a great deal of time and dedication with very little reward financially or appreciation from the administration may also be a deterrent 
to a minority athletic trainer. ${ }^{12}$ This research shows agreement with this concept because many participant responses indicated that potential salary did factor into their decision to choose this profession.

Research question 3 (RQ3): What factors influence minority students' decisions to choose athletic training as a major?

Research question 4 (RQ4): What factors influence White, non-Hispanic students' decisions to choose athletic training as a major?

When looking at the factors which influence the decision of minority and White students to choose athletic training as a major, the research found a couple of specific factors which were significantly different for these groups. Minority participants indicated a higher response in the desire to affect the health of patients who are of a similar race or ethnicity $(p=.020)$. White participants indicted that the influence of a college counselor or advisor was significantly higher than the minority respondents $(p=.045)$. This survey data was validated further by the interview responses where many of the White participants mentioned their academic advisor as a positive influence on their decision to choose the athletic training major. Participant 5 stated, "I was in my freshman year of college, and I was Undeclared and the advisor that I have said that she thought I would be a good fit for that major." Patient populations have reported better outcomes from practitioners who are of the same racial or ethnic backgrounds, so the desire of the minority students to work with these populations can be considered as a positive influence upon which athletic training programs can capitalize. It is also recommended that programs explore how advisors and college counselors perceive athletic training, because of the higher influence these individuals had on the White students. The academic programs can interpret this data as there 
being a genuine issue of how academic advising and college counselors are directing students toward the athletic training major. This is the first concept of critical race theory which states that organizations must recognize that some type of racial bias exists. ${ }^{3}$

Research question 5 (RQ5): What factors do minority students perceive as barriers when choosing athletic training as a major?

Research question 6 (RQ6): What factors do White, non-Hispanic students perceive as barriers when choosing athletic training as a major?

Looking at potential barriers that students perceive to becoming an athletic trainer, this study found that the attitudes of program faculty toward diversity did play a significant role for minority students, especially Black or African-American students $(p=.003)$. This concurs with research by Mazerolle ${ }^{8}$ which showed that faculty support was a major factor in determining the success of a student successfully transitioning into a professional practitioner. Interview participants did not seem to be concerned with diversity in their programs, but each student indicated a lack of diverse role models in athletic training. All students stated that they had never been exposed to any faculty member or preceptor other than White. This perceived lack of diversity may potentially be driving other minority students away from athletic training, and further effort in this area to include minority students in similar majors in the research should be explored.

This research has demonstrated that race plays a critical role in the decision-making process of minority students when choosing their profession. Crenshaw ${ }^{2}$ shows that racial inequity cannot be addressed from within most organizational structures, and this is certainly true for the profession of athletic training. This research shows us that potential and current students 
are not being exposed to diverse professionals. This is primarily due to the lack of these individuals, so it cannot be reasonably recommended that diversity be increased in their faculty and staff for the programs. This should be a secondary goal, but to change the profession, recruitment of diverse students should be the primary concern. 


\section{References}

1. Barfield J, Cobler D, Lam E, Zhang J, Chitiyo G. Differences between African-American and Caucasian students on enrollment influences and barriers in kinesiology-based allied health education programs. Advances in Physiology Education [serial online]. June 2012;36(2):164-169.

2. Crenshaw KW, Race, Reform, and Retrenchment: Transformation and Legitimation in Antidiscrimination Law. Harvard Law Review, 1988;101(7):1331-1387Available from: http://www.jstor.org/stable/1341398.

3. Delgado R, Stefancic J. Critical race theory: An introduction. NYU Press. 2012.

4. Ethnic Diversity Advisory Committee. EDAC demographic analysis 1997-2008. 2010. Retrieved from: http://www.nata.org/sites/default/files/EDAC-Demographic-Analysis1997-2008.pdf.

5. Hoffman K, Donoghue J, Duffield C. Decision-making in clinical nursing: investigating contributing factors. Journal of Advanced Nursing. 2004 Jan 1;45(1):53-62.

6. Ladson-Billings G. Just what is critical race theory and what's it doing in a nice field like education?. International journal of qualitative studies in education. 1998 Jan 1;11(1):724.

7. Laerd Statistics. Kruskal-Wallis H test using SPSS statistics. Statistical tutorials and software guides. (2015) Retrieved from: https://statistics.laerd.com/.

8. Mazerolle S, Gavin K, Pitney W, Casa D, Burton L. Undergraduate Athletic Training Students' Influences on Career Decisions After Graduation. Journal Of Athletic Training (Allen Press) [serial online]. November 2012;47(6):679-693. 
9. Melia KM. Learning and working: the occupational socialization of nurses. Routledge; 1987.

10. Mooney M. Professional socialization: The key to survival as a newly qualified nurse. International Journal Of Nursing Practice [serial online]. April 2007;13(2):75-80.

11. National Athletic Trainers' Association. ATEJ Authors Guide.2010 (March) Retrieved fromhttp://natajournals.org/userimages/ContentEditor/1399481120285/AuthorsGuide.pdf

12. Pitney W, Ilsley P, Rintala J. The Professional Socialization of Certified Athletic Trainers in the National Collegiate Athletic Association Division I Context. Journal Of Athletic Training (National Athletic Trainers' Association) [serial online]. January 2002;37(1):63.

13. Saldana J. An introduction to codes and coding. The coding manual for qualitative researchers. 2009:1-31.

14. Secrest JA, Norwood BR, Keatley VM. " I was actually a nurse": The meaning of professionalism for baccalaureate nursing students. Journal of Nursing Education. 2003 Feb 1;42(2):77-82.

15. Sullivan LW, Mittman IS. The state of diversity in the health professions a century after Flexner. Academic Medicine. 2010 Feb 1;85(2):246-53.

16. Toit D. A sociological analysis of the extent and influence of professional socialization on the development of a nursing identity among nursing students at two universities in Brisbane, Australia. Journal of advanced nursing. 1995 Jan 1;21(1):164-71. 
Section Six:

Scholarly Practitioner Reflection 


\section{How has the dissertation influenced your practice as an educational leader?}

As a practitioner, this process has changed the way in which I reflect about my decisionmaking process. As the director of the athletic training program, it is my responsibility to provide guidance to all our students, and to set policy for the program that will ensure our overall success. There is so much focus in education on the first-time pass rate for athletic training programs that most program goals are somehow aligned with this one primary goal. This process has made me step back from the focus on the test and examine where the strengths and weaknesses are in my program. I have begun to think of the athletic training program as an organization within the overall structure of the university. While I answer to those who are above me in the hierarchy of administration, I am solely responsible for the successes and failures of my program.

To this end, this research has shown me that the apparent lack of minorities in athletic training is not just a casual observation but a specific problem. While I can always represent myself to my students in a professional manner and hope that they would try to emulate my behavior, I cannot be the role model that some of my minority students are searching for in the profession. This was apparent to me from a guest speaker which the department of Health, Human Performance, and Recreation had invited to campus in the fall. He was an AfricanAmerican athletic training alumni that had become a successful professor and had started his own foundation in the St. Louis area. I observed that during his talk, the minority students in my program were engaged in a manner that I had never seen out of them in the classroom. Many of the students stayed after the talk with our guest, and I realized that this was a role model in the profession that they had never seen. 
As discussed in my research, the problem of changing the diversity of the profession cannot be attacked from within the profession itself. The solutions must come from outside of the profession. This has made me more determined than ever to increase my own efforts to improve the diversity of our athletic training program. I have already implemented the recommended policy changes at Southeast Missouri State University. I hope that after assessing their effectiveness over a few years, I can take that information and present our successes and failures to other educators and encourage similar policies in their programs. Only through education can we improve the diversity of those entering the field of athletic training. As these diverse students successfully transition into professionals, I fully believe that we will see a positive change in our profession that will move us into alignment with other similar allied healthcare fields.

\section{How has the dissertation process influenced you as a scholar?}

It has always been my intention to use this doctoral program as a means of progressing from a faculty position into administration. My lack of experience with research has always been a problem which has hung over me in my career. I have a very specific set of knowledge and abilities which is important to successfully teaching others in my field, but the larger academic community needs to see scholarship. This research has opened a new pathway of inquiry for me. Until I entered the ELPA doctoral program, I had always thought that any research in which I participated had to be focused on clinical applications and techniques for my profession.

Through the dissertation process I have learned that there is value in researching the broader issues of how to educate students in athletic training. I have even begun to keep a running list of ideas that have come to me through this research for future studies that I would be interested in pursuing. 
Several future inquiries have developed directly from the research that I have done for this dissertation. The comparison of gender and gender bias in athletic training has been explored to a small degree, but how the different genders view the profession and their opportunity for advancement is a question which has showed some promise based upon the participants' responses. Attitudes and biases of current athletic trainers towards other professionals of different sexual orientations has never been explored in research. This minority group is not protected under federal law, but anecdotally I have worked with enough athletic trainers who have identified themselves as homosexual to wonder how they perceive the profession. I believe that it would be very interesting to look at the field from their point of view.

My interest in performing more research has been piqued by this process, but I feel like I am in my early undeveloped stage. I need to continue to write and refine my own process to become more comfortable. This program has shown me the importance of qualitative information and how it can supplement our understanding of the quantitative data we analyze. I have already had some offers from peers to work on publishing now that my doctoral program has come to its completion, and I look forward to seeing where my own lines of inquiry take me. 


\section{References}

Barfield, J. P., Cobler, D. C., Lam, E. T., Zhang, J., \& Chitiyo, G. (2012). Differences between African-American and Caucasian students on enrollment influences and barriers in kinesiology-based allied health education programs. Advanced Physiology in Education, 36(2), 164-169. doi: 10.1152/advan.00129.2011

Bialocerkowski, A., Wells, C., \& Grimmer-Somers, K. (2011). Teaching physiotherapy skills in culturally-diverse classes. BMC Medical Education, 11, 34. doi: 10.1186/1472-6920-1134

Crenshaw, K. W. (1988). Race, reform, and retrenchment: Transformation and legitimation in antidiscrimination law. Harvard Law Review, 1331-1387.

Commission for the Accreditation of Athletic Training Education. (2012). Standards for the accreditation of professional athletic training programs. Retrieved from `http://caate.net/wp-content/uploads/2017/01/2012-Professional-Standards.pdf.

Delgado, R., \& Stefancic, J. (2012). Critical race theory: An introduction. NYU Press.

Ebel, R. G. (1999). Far beyond the shoe box: Fifty years of the National Athletic Trainers' Association. Forbes Custom Publishing.

Ethnic Diversity Advisory Committee. (2010). EDAC demographic analysis 1997-2008. Retrieved from http://www.nata.org/sites/default/files/EDAC-Demographic-Analysis1997-2008.pdf.

Geisler, P. R. (2003). Multiculturalism and athletic training education: implications for educational and professional progress. Journal of Athletic Training, 38(2), 141-151.

Grantham, J. (2015, February). Cultural competence and diversity in athletic training. NATA News. 10-12. 
Henry, P. (2006). Educational and career barriers to the medical profession: Perceptions of underrepresented minority students. College Student Journal, 40(2), 429-441.

Hoffman, K., Donoghue, J., \& Duffield, C. (2004). Decision-making in clinical nursing: investigating contributing factors. Journal of Advanced Nursing, 45(1), 53-62.

Hoodless, P. (2004). 'Are you just helping?' The perceptions and experiences of minority ethnic trainees on a one-year primary initial teacher training course. Research in Education, 72(1), 32-46.

Hung, R., McClendon, J., Henderson, A., Evans, Y., Colquitt, R., \& Saha, S. (2007). Student Perspectives on Diversity and the Cultural Climate at a U.S. Medical School. Academic Medicine, 82(2), 184-192 110.1097/ACM.1090b1013e31802d31936a.

Jackson, S. E. (1992) Diversity in the workplace: Human resources initiatives. The professional practice series. New York: Guilford Press

Ladson-Billings, G. (1998). Just what is critical race theory and what's it doing in a nice field like education?. International journal of qualitative studies in education, 11(1), 7-24.

Laerd Statistics (2015). Kruskal-Wallis H test using SPSS Statistics. Statistical tutorials and software guides. Retrieved from https://statistics.laerd.com/

Lindquist, M., Arrington, S., \& Scheopner, K. (2007). The BOC exam: The first 40 years. Jacob North Printing Company.

Marra, J., Covassin, T., Shingles, R. R., Canady, R. B., \& Mackowiak, T. (2010). Assessment of certified athletic trainers' levels of cultural competence in the delivery of health care. Journal of Athletic Training, 45(4), 380-385. doi: 10.4085/1062-6050-45.4.380

Martin, M., \& Buxton, B. (1997). The 21st-century college student: implications for athletic training education programs. Journal of Athletic Training, 32(1), 52-54. 
Maurer-Starks, S. S., Clemons, H. L., \& Whalen, S. L. (2008). Managing heteronormativity and homonegativity in athletic training: in and beyond the classroom. Journal of Athletic Training, 43(3), 326-336. doi: 10.4085/1062-6050-43.3.326

Mazerolle, S. M., Gavin, K. E., Pitney, W. A., Casa, D. J., \& Burton, L. (2012). Undergraduate athletic training students' influences on career decisions after graduation. Journal of Athletic Training, 47(6), 679-693. doi: 10.4085/1062-6050-47.5.16

Melia, K. M. (1987). Learning and working: the occupational socialization of nurses (Vol. 372). Routledge.

Melillo, K. D., Dowling, J., Abdallah, L., Findeisen, M., \& Knight, M. (2013). Bring diversity to nursing: Recruitment, retention, and graduation of nursing students. Journal of Cultural Diversity, 20(2), 100-104.

Mooney, M. (2007). Professional socialization: the key to survival as a newly qualified nurse. International Journal of Nursing Practice, 13(2), 75-80.

National Athletic Trainers' Association. (2010, March). ATEJ Authors Guide. Retrieved from http://natajournals.org/userimages/ContentEditor/1399481120285/AuthorsGuide.pdf

Pitney, W. A., Ilsley, P., \& Rintala, J. (2002). The professional socialization of certified athletic trainers in the national collegiate athletic association division I context. Journal of Athletic Training, 37(1), 63-70. Retrieved from http://search.proquest.com/docview/206644478?accountid=38003

Prentice, W. E. (2014). Principles of athletic training: A competency based approach (15 ${ }^{\text {th }}$ ed.). New York: McGraw Hill.

Saldana, J. (2009). An introduction to codes and coding. The coding manual for qualitative researchers, $1-31$. 
Schaeffer, R. T. (n.d.). What is a minority group? Retrieved from http://www.racism.org/index.php?option=com_content\&view=article\&id=280:minor010 $1 \&$ catid=15\&Itemid=118.

Secrest, J. A., Norwood, B. R., \& Keatley, V. M. (2003). " I was actually a nurse": The meaning of professionalism for baccalaureate nursing students. Journal of Nursing Education, $42(2), 77-82$.

Sullivan, L. W., \& Mittman, I. S. (2010). The state of diversity in the health professions a century after Flexner. Academic Medicine, 85(2), 246-253.

Toit, D. (1995). A sociological analysis of the extent and influence of professional socialization on the development of a nursing identity among nursing students at two universities in Brisbane, Australia. Journal of advanced nursing, 21(1), 164-171. 


\section{Appendix A}

\section{Scale for Allied Health Enrollment Decision (SAHED)}

Instructions: Please indicate on scale provided by circling the number which corresponds with your perception of the importance of the item with your decision to enroll in your major. ( $1=$ no influence to 5 = major influence)

\section{Personal Influence}

High School Teacher

No influence 1

3

4

$5 \quad$ Major Influence

High School Counselor

No influence 1

3

4

$5 \quad$ Major Influence

College Teacher

No influence 1

2

3

4

$5 \quad$ Major Influence

College Counselor

No influence 1

2

3

4

$5 \quad$ Major Influence

\section{Social Influence}

Social interaction in the program

No influence 1 2

3

4

$5 \quad$ Major Influence

Diversity of students in the program

No influence 1

2

3

4

$5 \quad$ Major Influence

Media (portrayal in television, newspapers)

No influence 1

2

3

4

$5 \quad$ Major Influence

Background knowledge before enrollment

No influence 1

2

3

4

$5 \quad$ Major Influence 


\section{Academic Preparation}

High school academic performance

No influence 1

2

4

$5 \quad$ Major Influence

Performance in high school science classes

No influence 1

2

3

4

5

Major Influence

Performance in high school math classes

No influence 1

2

4

$5 \quad$ Major Influence

\section{Career Opportunity}

Potential success in the field

No influence 1

2

3

4

$5 \quad$ Major Influence

Potential to make a good salary in the field

No influence 1

2

3

4

5

Major Influence

Interest in degree program

No influence 1

2

3

4

$5 \quad$ Major Influence

\section{Individual Aspiration}

Desire to help others

No influence

2

3

4

$5 \quad$ Major Influence

Desire to affect the health of others

No influence 1

2

3

4

5

Major Influence

Desire to affect the health of minorities

No influence 1

2

3

4

5 Major Influence 


\section{Physical Self-Efficacy}

High school athletic experience

No influence 1

2

3

Performance in high school physical education
2

Success in sport
2
4

4

4
5

Major Influence

3

3
5

Major Influence

5

Major Influence 


\section{Appendix B}

\section{Scale for Allied Health Enrollment Barrier (SAHEB)}

Instructions: Please indicate on scale provided by circling the number which corresponds with your perception of the importance of the item as a barrier to enrolling in your major. $(1=$ no influence to $5=$ major influence)

\section{Social Influence}

A high school teacher

No influence 1

A high school counselor
No influence 1
A college teacher

2

3

4

$5 \quad$ Major Influence
No influence 1
A college counselor

2

3

4

5

Major Influence

No influence 1

2

3

4

$5 \quad$ Major Influence

A high school or college coach

No influence 1

2

3

4

$5 \quad$ Major Influence

A sibling

No influence 1 2

3

4

$5 \quad$ Major Influence

Attitudes of faculty toward race or culture

No influence 1

2

3

4

$5 \quad$ Major Influence

\section{Experiential Opportunity}

Availability of role models field same ethnicity
No influence 1
2
3
4
$5 \quad$ Major Influence

Access to part-time jobs in the field

No influence

2

3

4

5

Major Influence

Access to job shadowing 
Scholarship available for the major

No influence 1

2

3

4

$5 \quad$ Major Influence

\title{
Academic Preparation
}

High school academic performance

\begin{tabular}{|c|c|c|c|c|c|c|}
\hline No influence & 1 & 2 & 3 & 4 & 5 & Major Influence \\
\hline \multicolumn{7}{|c|}{ Performance in high school science classes } \\
\hline No influence & 1 & 2 & 3 & 4 & 5 & Major Influence \\
\hline \multicolumn{7}{|c|}{ Performance in high school math classes } \\
\hline No influence & 1 & 2 & 3 & 4 & 5 & Major Influence \\
\hline
\end{tabular}

\section{Physical Self-Efficacy}

Athletic ability

No influence 1

2

3

4

$5 \quad$ Major Influence

Physical fitness level

No influence 1

Major Influence

Personal health

No influence 1

\section{Self-Management}

Course difficulty in the major

\author{
No influence 1 \\ 2 \\ Workload in required courses
}

3

4

$5 \quad$ Major Influence

\author{
No influence 1
}

2

3

4

5

Major Influence 
Study skills

No influence 1

Overall stress of being in the major
2

Obligations outside the major (work)
No influence 1
3

3

4

4

4

3
5

Major Influence
$5 \quad$ Major Influence

$5 \quad$ Major Influence 


\section{Appendix C}

\section{Demographic Information}

Year in Athletic Training Program (Please circle one choice)
Pre-Professional
$1^{\text {st }}$ Year
$2^{\text {nd }}$ Year
$3^{\text {rd }}$ Year

Gender

Male Female

\section{Race/Ethnicity}

White/Non-Hispanic

American Indian
Hispanic or Latino

Alaskan Native
Black

Asian

\section{Pacific Islander}

Please indicate if you would be willing to be contacted for an interview either in-person or by video (Skype).

Yes No

If you answered Yes, please give contact information (this information will not be connected to your responses on this survey or used for any means other than to contact you for an interview)

Name

Email

Phone 


\section{Appendix D}

\section{Questions for Semi-Structured Interview of Subjects}

1. Who had the greatest influence on your decision to choose athletic training as a major?

2. How did the diversity of the athletic training program at your institution affect your decision to enroll in this major?

3. What exposure to the profession of athletic training did you have prior to enrollment?

4. How does your program prepare you to transition from student to professional practitioner?

5. What do you perceive as the biggest obstacle for minority students to enter the field of athletic training?

6. In what ways do outside obligations (i.e., work or family) affect your ability to be successful in this major?

7. What exposure have you had to athletic training professionals who are of your same ethnicity and did this influence your decision to become an athletic trainer?

8. What are the differences in the interactions between professional athletic trainers and White or minority students?

9. To what extent does the potential salary for an athletic trainer affect your desire to enter the profession? 


\section{Appendix E}

\section{Tables and figures}

\section{Table 1}

Accredited bachelors of athletic training programs in Missouri

Central Methodist University

Culver-Stockton College

Lindenwood University

Missouri State University

Missouri Valley College

Southeast Missouri State University

Southwest Baptist University

University of Central Missouri

University of Missouri

William Woods University 
Table 2

Attribute coding of interview participants

\begin{tabular}{cclc}
\hline Alias & Race or Ethnicity & Gender & Interview Format \\
\hline Participant 1 & Black or African-American & Female & In-Person \\
Participant 2 & Asian & Female & In-Person \\
Participant 3 & White & Male & In-Person \\
Participant 4 & White & Female & In-Person \\
Participant 5 & White & Male & Skype \\
Participant 6 & Asian & Female & Skype \\
Participant 7 & Hawaiian or Pacific Islander & Female & Skype \\
Participant 8 & Black or African-American & Female & Skype \\
\hline
\end{tabular}


Figure 1

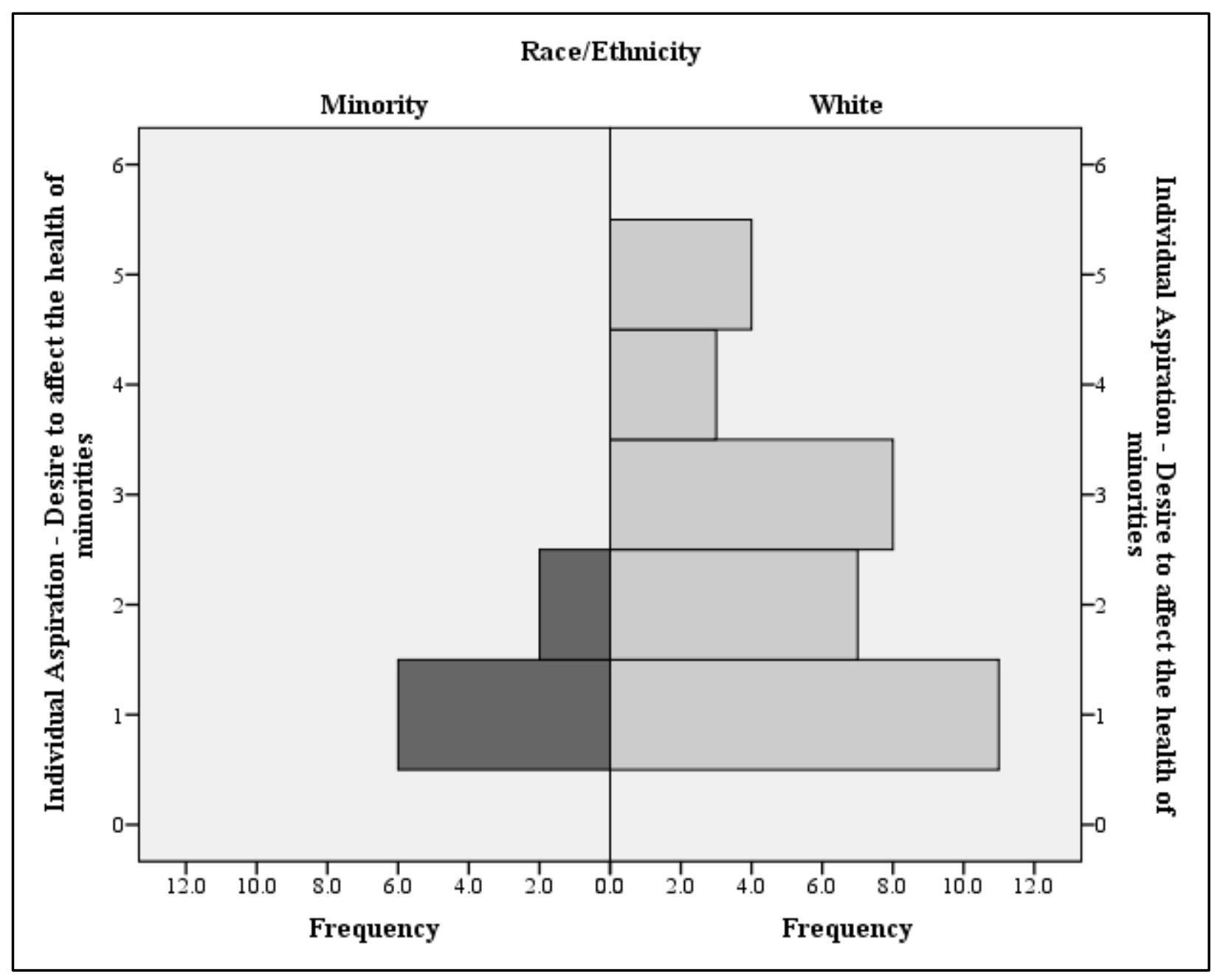


Figure 2

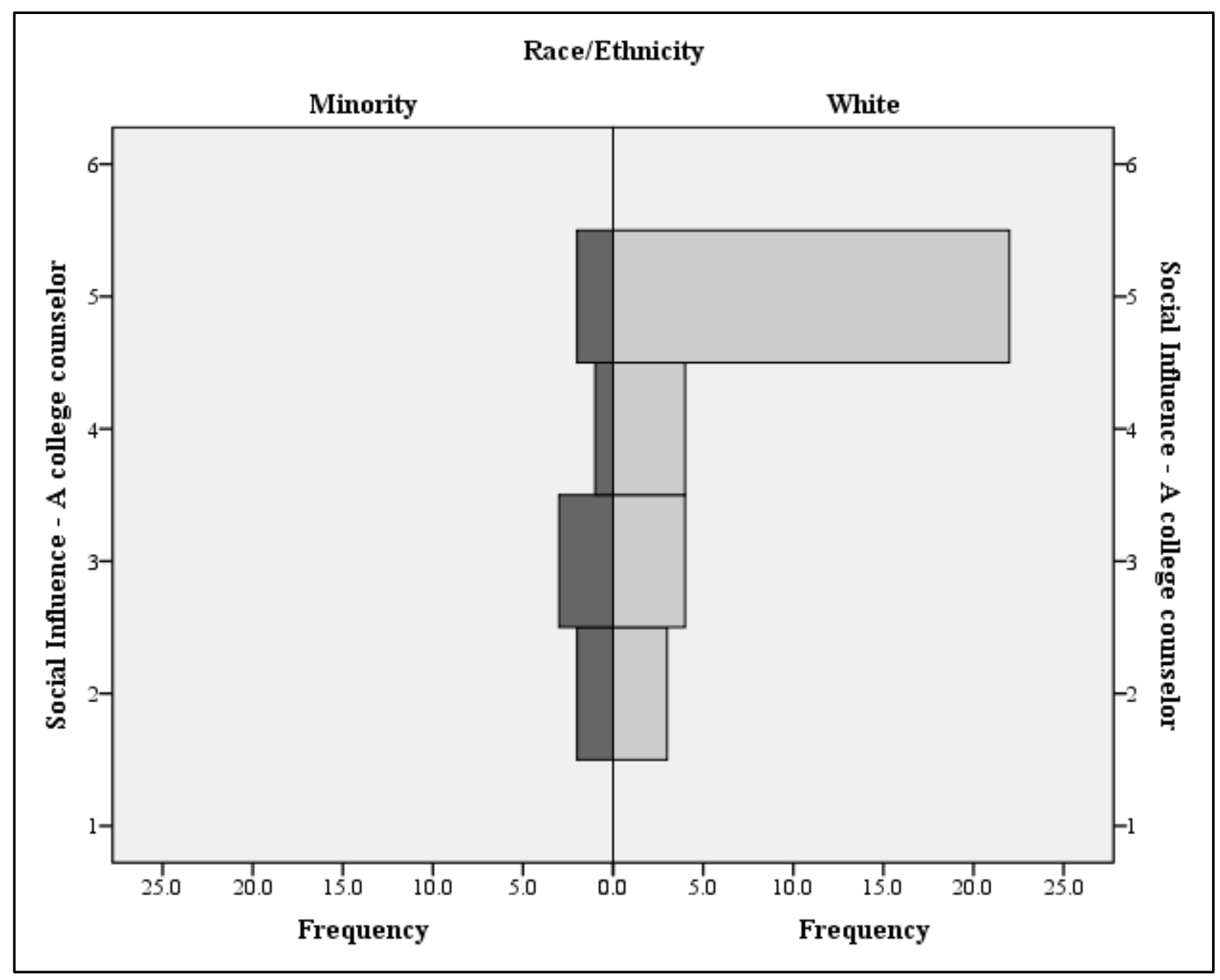


Figure 3

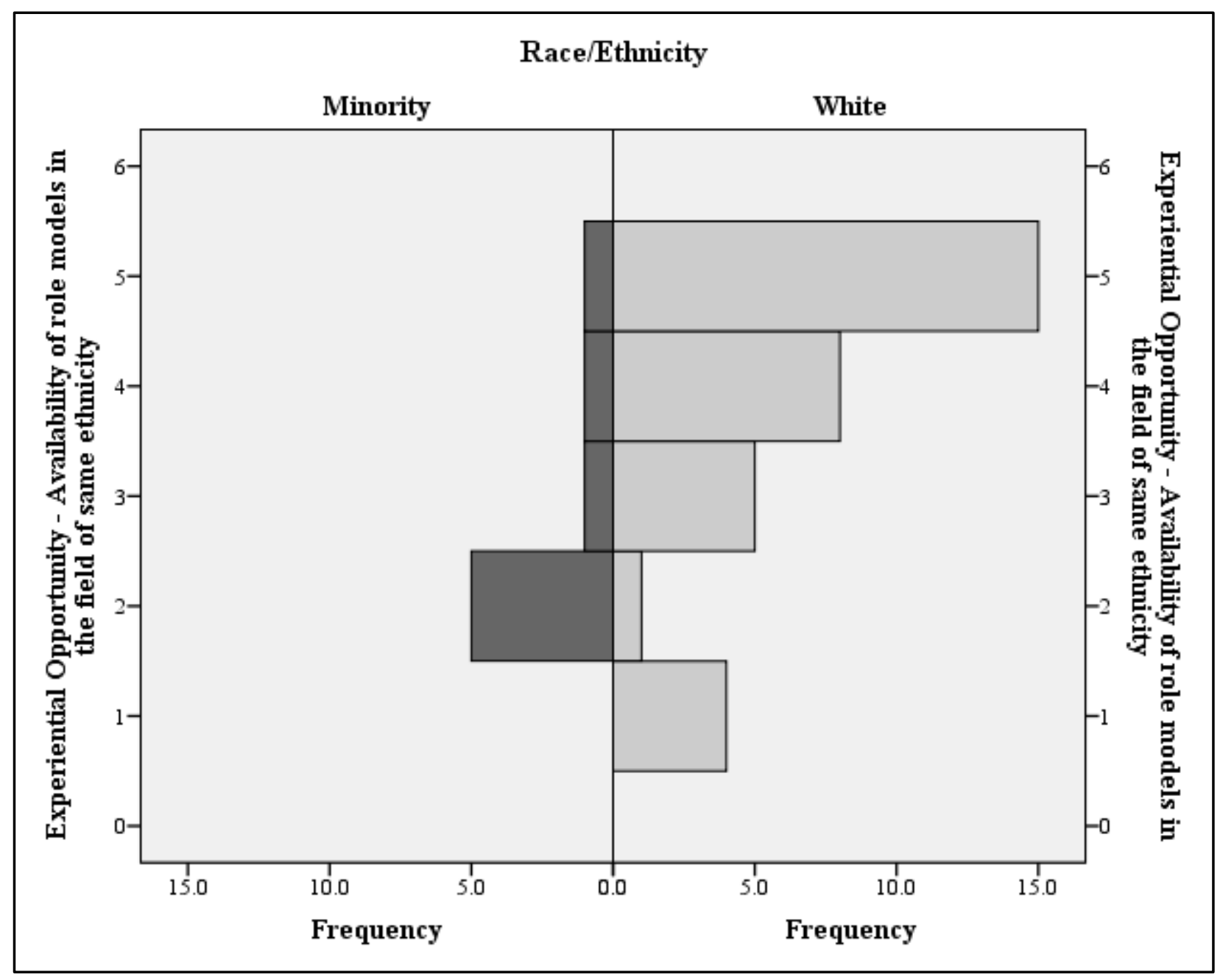




\section{VITA}

Stephen Nickell is currently the Director of the Athletic Training Education Program at Southeast Missouri State University in Cape Girardeau, MO. Prior to his current position, he was the Chair of Sports Studies at Urbana University in Urbana, OH. Stephen graduated with his Bachelor of Science in Athletic Training (BSAT) from Ohio University in 1999. He received his Master of Arts from Rider University in Human Services Administration in 2001. Stephen has been a certified and licensed athletic trainer for 18 years and has worked with patients at every level of athletic participation. He currently resides in Cape Girardeau, MO with his wife and four children. 